\title{
GEOMORFOMETRÍA DE CUENCAS DE DRENAJE DE LA VERTIENTE NORTE DEL MACIZO “EL ÁVILA” (ESTADO VARGAS, VENEZUELA): IMPLICACIONES HIDROMORFODINÁMICAS
}

\author{
GEOMORPHOMETRY OF WATERSHEDS OF THE MASSIF "EL \\ ÁVILA” NORTHERN HILLSIDE (VARGAS STATE, VENEZUELA): \\ HYDROMORPHODYNAMIC IMPLICATIONS
}

\author{
Williams José Méndez Mata \\ Departamento de Ciencias de la Tierra, Universidad Pedagógica Experimental Libertador \\ Avenida Páez, El Paraíso 1020, Caracas, Distrito Capital, Venezuela \\ Email:williamsmendez@gmail.com
}

Juan Manuel Carrera Ramos

Centro de Oceanología y Estudios Antárticos, Instituto Venezolano de Investigaciones Científicas Carretera Panamericana, Kilómetro 11, Caracas 1020-A, Altos de Pipe, Miranda, Venezuela Email: juan.jmcr14@gmail.com

Larry José Rivas Rodríguez

Departamento de Ciencias de la Tierra, Universidad Pedagógica Experimental Libertador Avenida Páez, El Paraíso 1020, Caracas, Distrito Capital, Venezuela

Email: rivaslarry@gmail.com

\section{Informações sobre o Artigo}

Data de Recebimento:

31/03/2015

Data de Aprovação:

04/07/2015

\section{Palavras-chave:}

Geomorfometría, cuenca de drenaje, hidromorfodinámica.

\section{Keywords:}

Geomorphometry, watershed, hydromorphodynamic.

\section{Resumo:}

Entre otros diversos aspectos, el evento de aludes torrenciales de Diciembre de 1999 evidenció a partir de los volúmenes de sedimentos depositados por éstos y la severidad de los daños causados, con diferencias notorias entre distintos sectores del litoral varguense afectado, que existen elementos del medio físico que controlan las características y magnitudes de las respuestas hidrológicas de las cuencas de drenaje. Es por ello que el propósito de este trabajo se centra en el análisis e interpretación de los parámetros morfométricos (geomorfometría) de las cuencas y redes de drenaje de un sector de la vertiente norte del macizo "El Ávila" (estado Vargas, Venezuela), en términos de sus incidencias e implicaciones en las dinámicas hidrológica y geomorfológica de los sistemas estudiados. La metodología consistió básicamente en estimaciones, mediciones y cálculos de los parámetros morfométricos de las cuencas y sus redes de drenaje sobre la cartografía base digitalizada del sector de estudio seleccionado, con apoyo en la herramienta para SIG software ArcGIS 9.2 y sus módulos Spatial Analysis y ArcHydro y el software Microsoft Excel. Se realizó un análisis descriptivo de los datos de los parámetros morfométricos, cuyos estadísticos fueron estimados con el complemento Xlstat de Microsoft Excel. Estos sistemas hidrogeomorfológicos 
califican en la categoría de microcuencas debido a sus pequeñas dimensiones, son espacios topográficamente muy accidentados de fuertes pendientes y grandes desniveles altitudinales, y corresponden a sistemas de morfologías planimétricas semi-circulares a semi-alargadas. Las cuencas de drenaje estudiadas albergan redes de desagüe de ramificaciones y densidades considerables con cortas longitudes y canales de escasa sinuosidad (rectilíneos), que se corresponden con sistemas de altas magnitudes y órdenes, así como elevados niveles de torrencialidad. En síntesis, las respuestas morfodinámicas e hidrológicas de las cuencas estudiadas son condicionadas y controladas por sus parámetros morfométricos y los de sus redes de drenaje.

\begin{abstract}
:
Among various other aspects, the event of debris flows December 1999 showed from the volumes of sediments deposited by them and the severity of the damage, with marked differences between different sectors of the affected coastline varguense, there are elements of the physical environment that control the characteristics and magnitudes of hydrological responses of the watersheds. That is why the purpose of this work focuses on the analysis and interpretation of morphometric parameters (geomorphometry) of the watersheds and drainage networks from one sector of the northern hillside of the Massif "El Ávila" (Vargas State, Venezuela), in terms of their impact and implications on hydrological and geomorphological dynamics of the systems studied. The methodology was basically estimates, measurements and calculations of morphometric parameters of the basins and drainage networks on the digitized maps of the selected area, with support in the tool for GIS ArcGIS 9.2 software and their Spatial Analysis and ArcHydro modules and Microsoft Excel software. A descriptive analysis of the morphometric parameters data was performed, whose statistics were estimated with the Xlstat of Microsoft Excel. These hydrogeomorphological systems qualify in the category of micro-watersheds due to its small size, are topographically very hilly areas with steep slopes and large altitude slopes, and are systems of semi-circular to semi-oblong planimetric morphologies. Watersheds studied home drainage networks of considerable branches and densities with short lengths and low sinuosity channels (straight), corresponding to high magnitudes and order systems, and high levels of torrential. In short, the geomorphological and hydrological responses of the watersheds studied are conditioned and controlled by their morphometric parameters and their drainage networks.
\end{abstract}

\section{Introducción}

El incremento poblacional así como la ocupación irracional y desproporcionada -en muchos de los casos- de la tierra en el espacio venezolano aunado a la ubicación geográfica de su territorio, determinan condiciones de vulnerabilidad y riesgo para sus habitantes $\mathrm{y}$ altas probabilidades de ocurrencia de desastres socio-naturales. Venezuela es un país expuesto a los impactos de diversas amenazas naturales, de las cuales con mayor frecuencia ocurren escenarios vinculados a inundaciones, crecientes, deslizamientos y aludes torrenciales. Los mayores impactos de este panorama acontecen principalmente en las regiones costeras y montañosas del país, donde se concentra la mayor proporción de la población venezolana.

De los eventos de aludes torrenciales ocurridos en el territorio nacional, el que más destaca por su magnitud y efectos es el de Diciembre de 1999 (estado Vargas), atribuido a las intensas y prolongadas precipitaciones registradas durante los días 14,15 y 16 de ese mes y año, que afectaron principalmente la vertiente norcaribeña de la Cordillera de la Costa en el tramo correspondiente a la Serranía de El Ávila, y que estuvieron relacionadas con una situación meteorológica tipo vaguada en altura (ANDRESSEN; PULWARTY, 2001; FOGHIN, 2001; GONZÁLEZ; CÓRDOVA, 2006; HIDALGO, 2006).

Entre otros diversos aspectos, el evento de aludes torrenciales de Diciembre de 1999 evidenció a partir de los volúmenes de sedimentos depositados por éstos y la severidad de los daños causados, con diferencias notorias entre distintos sectores del litoral varguense afectado, que existen elementos del medio físico que controlan las características y magnitudes de las respuestas hidrológicas de las cuencas de drenaje. En este sentido, el análisis morfométrico de una cuenca de drenaje permite analizar y comprender los elementos geométricos básicos del sistema, que ante la presencia de precipitaciones, interactúan para originar y/o activar procesos geomorfológicos (remoción en masa) de ver- 
tientes en materiales bajo condiciones de inestabilidad, $\mathrm{y}$ aludes torrenciales en los cauces de la red de drenaje (GUEVARA; CARTAYA, 2004; VÉLEZ; VÉLEZ, s. f.).

Entre algunos trabajos específicos que se han realizado sobre morfometría de cuencas y redes de drenaje y su control en las respuestas hidrológica y morfodinámica de éstas, caben destacar los de: Gouveia (2005); Potenciano y Garzón (2005); Méndez y Marcucci (2006); Silva et al. (2006); Ayala et al. (2007); Méndez et al. (2007); Esper (2008); Farfán et al. (2010); Genchi et al. (2011); Méndez et al. (2011); Campo et al. (2012); Romshoo et al. (2012) y Yunus et al. (2014).

Es por ello que el propósito de este trabajo se centra en el análisis e interpretación de los parámetros morfométricos (geomorfometría) de las cuencas y redes de drenaje de un sector de la vertiente norte del macizo
"El Ávila" (estado Vargas, Venezuela), en términos de sus incidencias e implicaciones en las dinámicas hidrológica y geomorfológica de los sistemas estudiados.

\section{Área de Estudio}

El área de estudio se ubica geográficamente en la Región Centro Norte del territorio venezolano en la parte central del estado Vargas, conformada por las cuencas de drenaje de las quebradas Curucutí, Piedra Azul, Osorio, Cariaco, El Cojo, Camurí Chiquito, San Julián y Seca y de los ríos San José de Galipán, Cerro Grande, Uria, Naiguatá y Camurí Grande. Geoastronómicamente está definida por las coordenadas: $10^{\circ} 32^{\prime} 25^{\prime \prime}$,

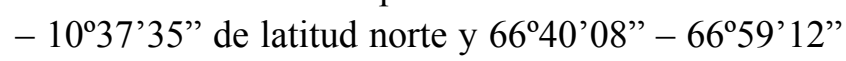
de longitud oeste (Figura 1).

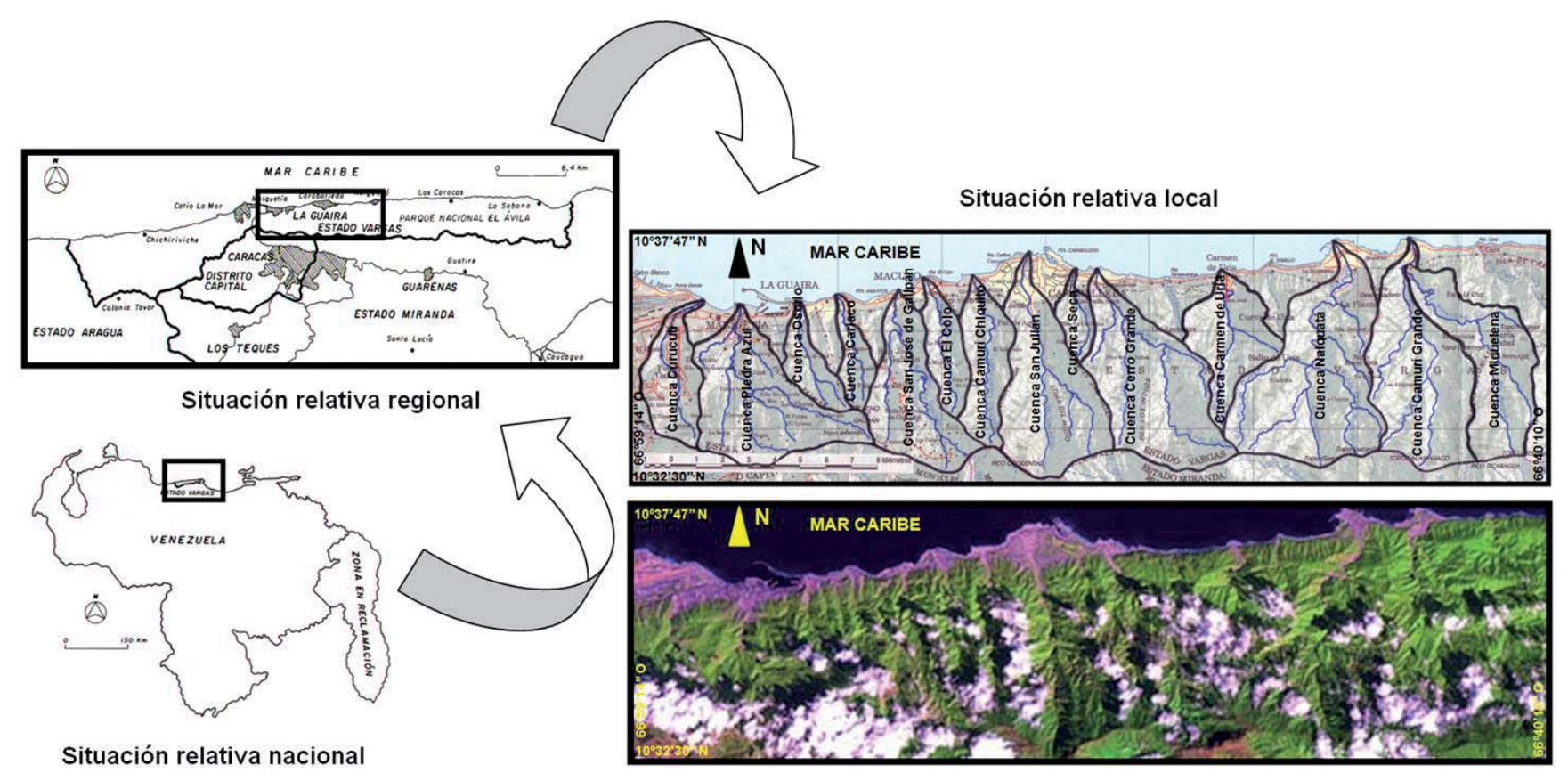

Figura 1 - Localización de las cuencas de drenaje del área de estudio, vertiente norte del macizo “El Ávila”, estado Vargas, Venezuela. Base cartográfica tomada del mapa "Caracas y alrededores” (mapa especial) a escala 1:100.000 por Instituto Geográfico de Venezuela Simón Bolívar [IGVSB], 2003, Caracas; e imagen del satélite “Landsat 7 ETM” por Centro de Procesamiento Digital de Imágenes [CPDI], 2002, Baruta.

El macizo "El Ávila" se extiende aproximadamente $100 \mathrm{~km}$ desde el valle tectónico de la quebrada Tacagua en el oeste hasta cabo Codera en el este. Empinado y abrupto este macizo se eleva entre el mar Caribe y los valles intramontanos de origen tectónico de Caracas y de Guarenas-Guatire, siendo su mayor elevación el Pico Naiguatá con 2.765 metros sobre el nivel del mar (msnm), cuyas unidades en conjunto constituyen un buen ejemplo de relieve controlado por bloques morfotectónicos (GUEVARA, 1983). La geología está constitutida por afloramientos de unidades litodémicas de las fajas Asociación Metamórfica Ávila (Augengneis de Peña de Mora, Complejo San Julián, Metatonalita de Caruao y Metagranito de Naiguatá) y Asociación 
Metamórfica La Costa (Serpentinita, Anfibolita de Nirgua, Esquisto de Tacagua, y Mármol de Antímano) (URBANI, 2000, 2002; URBANI et al., 2006).

El clima se caracteriza por presentar una temperatura media anual de $26,1^{\circ} \mathrm{C}$ en la parte baja del área, y entre $12,7^{\circ} \mathrm{C}$ y $22^{\circ} \mathrm{C}$ en la parte alta (MINISTERIO DEL PODER POPULAR PARA EL AMBIENTE [MPPA], 2011). Las precipitaciones son escasas con promedios anuales que superan los $500 \mathrm{~mm}$ (entre 530,5 mm y 859,6 mm) (MPPA, 2011), determinando categorías pluviométricas semi-árida para la parte baja y semi-húmeda para la parte alta. El sector está enmarcado en un tipo climático Bshi (Clima Tropical Estepario) para la parte baja (franja costera), y Aw (Clima Tropical de Sabana) para la parte alta (sector montañoso) de acuerdo con la clasificación de Köeppen (FOGHIN, 2002).

En las laderas bajas del área los suelos presentan deficiencias de humedad y clasifican como Haplargids y Torriorthents, y en las cumbres más altas se presentan suelos muy evolucionados y profundos que clasifican como Haplohumults (menor temperatura) y Hapludults (mayor humedad) (ELIZALDE et al., 2007). La vegetación está representada por las formaciones vegetación litoral, cardonales y espinares, bosque deciduo, bosque semi-deciduo, bosque transicional, selva nublada, sub-páramo, bosque de galería y vegetación secundaria (STEYERMARK; HUBER, 1978; AMEND, 1991).

\section{Materiales y Métodos}

La información cartográfica base (planos y cartas topográficas a escalas $1: 5.000$ y 1:25.000 respectivamente y ortofotomapas a escala 1:25.000) (DIRECCIÓN DE CARTOGRAFÍA NACIONAL [DCN], 1958, 1979; GOBERNACIÓN DEL DISTRITO FEDERAL [GDF], 1984; SERVICIO AUTÓNOMO DE GEOGRAFÍA Y CARTOGRAFÍA NACIONAL [SAGECAN], 1995) fue rasterizada, georreferenciada y digitalizada empleando el software ArcGIS 9.2. Se realzaron las redes de drenaje y se delimitaron los perímetros de las cuencas utilizando el módulo ArcHydro, y con el módulo Spatial Analysis se construyó el Modelo de Elevación Digital del Terreno (MEDT).

Sobre la cartografía digitalizada se levantaron los perfiles topográficos, paso que se complementó con el empleo del software Microsoft Excel, representando dichos perfiles (columnas con valores de distancia ho- rizontal acumulada en metros en el eje de las $x$ y valores de altitud o cotas en metros sobre el nivel del mar en el eje de las $y$ ) en gráficos de dispersión con puntos unidos por líneas.

Las mediciones y cálculos de los parámetros morfométricos básicos de las cuencas y sus redes de drenaje, se llevaron a cabo en un primer momento sobre la cartografía digitalizada, empleando la misma herramienta tecnológica para SIG, lo cual permitió obtener atributos o mediciones básicas con expresiones lineales, longitudinales, areales, altimétricas y clinométricas. La información morfométrica se organizó en bases de datos diseñadas con el software Microsoft Excel, y posteriormente con el empleo de las ecuaciones que definen al resto de los parámetros, se procedió a sus respectivas estimaciones. Estos parámetros se agruparon en las variables escala de la cuenca, gradiente y forma del relieve de la cuenca, forma de la cuenca, extensión de la red de drenaje y orden y magnitud de la red de drenaje (Tabla 1).

Los valores de algunos parámetros morfométricos fueron obtenidos por procedimientos específicos, de esta manera, la altitud media y la pendiente media del relieve de cada una de las cuencas fueron arrojados por el mismo software ArcGIS 9.2 con el Módulo Spatial Analysis, a partir de la cartografía base previamente digitalizada.

Las concavidades de cada uno de los perfiles topográficos longitudinales de los cauces de las quebradas y ríos principales, se obtuvieron con mediciones realizadas directamente sobre dichos perfiles, sustentadas básicamente en las diferencias altitudinales entre una línea recta trazada entre ambos extremos del perfil topográfico y la línea de este mismo en sus longitudes medianas, y divididas nuevamente entre la altitud de la línea recta en su longitud mediana.

Las pendientes medias de los perfiles topográficos longitudinales de los cauces de las quebradas y ríos principales, se estimaron en las mismas hojas de cálculo del software Microsoft Excel, mediante el ajuste gráfico de líneas o rectas de tendencia o de regresión sobre los perfiles de los cursos de agua en cuestión (previamente levantados de la misma manera como se levantaron los perfiles topográficos del relieve), cuyos primeros términos de las ecuaciones de la recta arrojados por el sistema, representan a las pendientes medias de dichos perfiles. 
Tabla 1: Parámetros morfométricos medidos, estimados y/o calculados en cuencas y redes de drenaje de la vertiente norte del macizo “El Ávila”, estado Vargas, Venezuela.

\begin{tabular}{|c|c|c|c|c|}
\hline Variable & Parámetro & Símbolo & Expresión & Unidades \\
\hline & 1. Área & A & $\begin{array}{l}\text { Se mide sobre el plano } \\
\text { (planímetro o SIG) }\end{array}$ & $\mathrm{km}^{2}$ \\
\hline & 2. Vertiente con mayor área & $V a_{\text {may }}$ & $\begin{array}{l}\text { Se mide sobre el plano } \\
\text { (planímetro o SIG) }\end{array}$ & $\mathrm{km}^{2}$ \\
\hline & 3. Vertiente con menor área & $V a_{m e n}$ & $\begin{array}{l}\text { Se mide sobre el plano } \\
\text { (planímetro o SIG) }\end{array}$ & $\mathrm{km}^{2}$ \\
\hline & 4. Perímetro & $P$ & $\begin{array}{l}\text { Se mide sobre el plano } \\
\text { (planímetro o SIG) }\end{array}$ & $\mathrm{km}$ \\
\hline & 5. Longitud & $L$ & $\begin{array}{l}\text { Se mide sobre el plano con } \\
\text { una regla o SIG }\end{array}$ & $\mathrm{km}$ \\
\hline \multirow[t]{8}{*}{$\begin{array}{l}\text { Escala de } \\
\text { la cuenca }\end{array}$} & 6. Ancho promedio & $a$ & $a=\frac{A}{L}$ & $\mathrm{~km}$ \\
\hline & 7. Ancho máximo & $a_{\text {máx }}$ & $\begin{array}{l}\text { Se mide sobre el plano } \\
\text { con una regla o SIG, } \\
\text { perpendicular a la longitud de } \\
\text { la cuenca }\end{array}$ & $\mathrm{km}$ \\
\hline & 8. Diámetro & $D$ & $D=\sqrt{\frac{4 A}{\pi}}$ & $\mathrm{km}$ \\
\hline & $\begin{array}{l}\text { 9. Área del rectángulo } \\
\text { equivalente al de la } \\
\text { cuenca }\end{array}$ & $A r$ & $A r=L a_{\text {máx }}$ & $\mathrm{km}^{2}$ \\
\hline & $\begin{array}{l}\text { 10. Perímetro de un círculo } \\
\text { igual al área de la cuenca }\end{array}$ & PC & $P_{C}=\pi \sqrt{\frac{4 A}{\pi}}$ & $\mathrm{km}$ \\
\hline & 11. Altitud mínima & $h$ & $\begin{array}{l}\text { Lectura de curvas de nivel en } \\
\text { el plano }\end{array}$ & $\mathrm{msnm}^{\mathrm{a}}$ \\
\hline & 12. Altitud máxima & $H$ & $\begin{array}{l}\text { Lectura de curvas de nivel en } \\
\text { el plano }\end{array}$ & msnm \\
\hline & 13. Altitud media & $H_{m}$ & $\begin{array}{l}\text { Estimada con el software } \\
\text { para SIG }\end{array}$ & msnm \\
\hline \multirow{5}{*}{$\begin{array}{l}\text { Gradiente } \\
\text { y forma del } \\
\text { relieve de } \\
\text { la cuenca }\end{array}$} & $\begin{array}{l}\text { 14. Altitud de la naciente de } \\
\text { la corriente principal }\end{array}$ & $H_{n}$ & $\begin{array}{l}\text { Lectura de curvas de nivel en } \\
\text { el plano }\end{array}$ & msnm \\
\hline & $\begin{array}{l}\text { 15. Altitud del desagüe de la } \\
\text { corriente principal }\end{array}$ & $h_{d}$ & $\begin{array}{l}\text { Lectura de curvas de nivel en } \\
\text { el plano }\end{array}$ & msnm \\
\hline & 16. Relieve máximo & $R m$ & $R m=H-h$ & $\mathrm{~m}$ \\
\hline & 17. Radio del relieve & $R$ & $R=\frac{R m}{L}$ & $\mathrm{~m} / \mathrm{km}$ \\
\hline & $\begin{array}{l}\text { 18. Pendiente media del } \\
\text { relieve }\end{array}$ & $P_{m}$ & $\begin{array}{l}\text { Estimada con el software } \\
\text { para SIG }\end{array}$ & $\mathrm{m} / \mathrm{m} \mathrm{o} \%$ \\
\hline
\end{tabular}




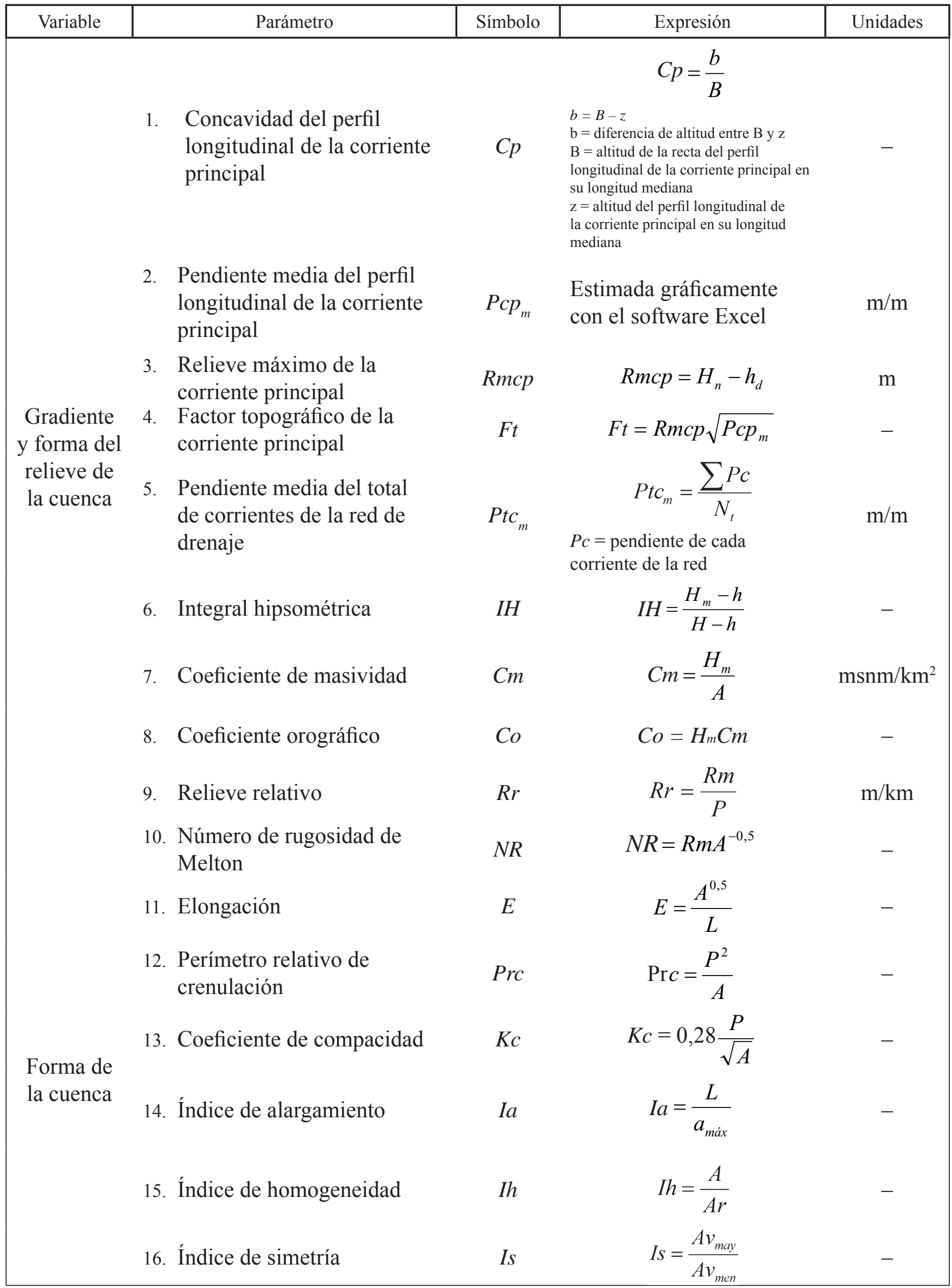




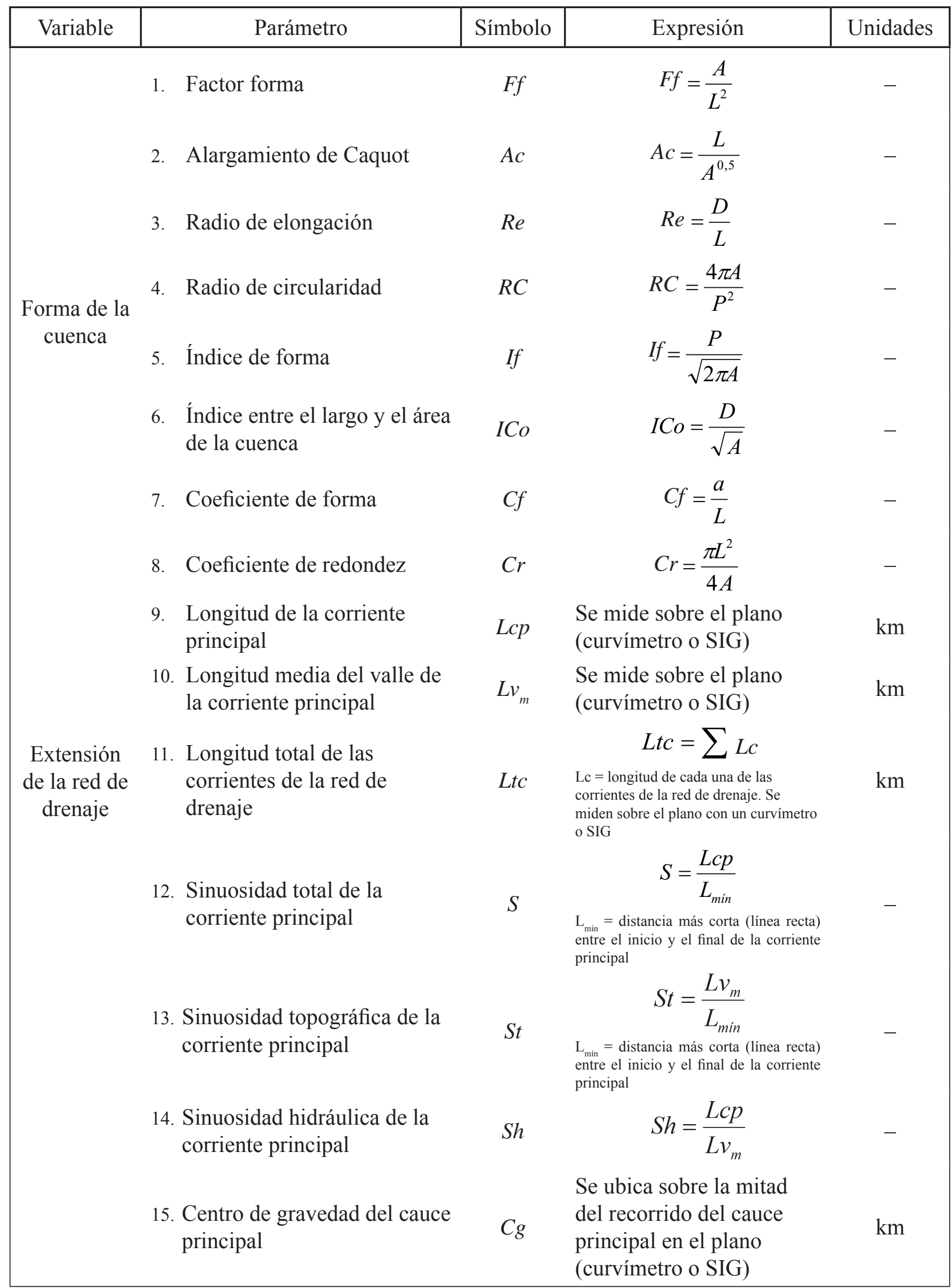




\begin{tabular}{|c|c|c|c|c|}
\hline Variable & Parámetro & Símbolo & Expresión & Unidades \\
\hline \multirow{9}{*}{$\begin{array}{l}\text { Extensión } \\
\text { de la red de } \\
\text { drenaje }\end{array}$} & 1. Densidad de drenaje & $D d$ & $D d=\frac{L t c}{A}$ & $\mathrm{~km} / \mathrm{km}^{2}$ \\
\hline & 2. Textura del drenaje & $T d$ & $T d=D d F_{m}$ & $\mathrm{~km}^{-1}$ \\
\hline & $\begin{array}{l}\text { 3. Coeficiente de } \\
\text { mantenimiento del canal }\end{array}$ & $\mathrm{Cmc}$ & $C m c=\frac{A}{L t c}$ & $\mathrm{~km}^{2} / \mathrm{km}$ \\
\hline & $\begin{array}{l}\text { 4. Extensión media de la } \\
\text { escorrentía superficial }\end{array}$ & $E_{m}$ & $E_{m}=\frac{A}{4 L t c}$ & $\mathrm{~km}$ \\
\hline & & & 1 & \\
\hline & $\begin{array}{l}\text { 5. Longitud del flujo } \\
\text { superficial }\end{array}$ & $L f s$ & $2 D d \sqrt{1-\frac{P t c_{m}}{P_{m}}}$ & $\mathrm{~km}$ \\
\hline & 6. Textura topográfica & $T t$ & $\log T t=0,219649+1,115 \log D d$ & - \\
\hline & 7. Intensidad de drenaje & Id & $I d=\frac{F m}{D d}$ & $\mathrm{~km}$ \\
\hline & 8. Alejamiento medio & $A m$ & $A m=\frac{L c p}{\sqrt{A}}$ & - \\
\hline \multirow{7}{*}{$\begin{array}{l}\text { Orden y } \\
\text { magnitud } \\
\text { de la red de } \\
\text { drenaje }\end{array}$} & 9. Orden de la corriente & $u$ & $\begin{array}{l}\text { Orden numérico o } \\
\text { jerarquización de los } \\
\text { segmentos de corriente, } \\
\text { dependiendo de su posición } \\
\text { en la red de drenaje }\end{array}$ & - \\
\hline & $\begin{array}{l}\text { 10. Número de corrientes de } \\
\text { un orden dado }\end{array}$ & $N_{u}$ & $\begin{array}{l}\text { Se contabilizan sobre el } \\
\text { plano }\end{array}$ & - \\
\hline & $\begin{array}{l}\text { 11. Número total de corrientes } \\
\text { de la red de drenaje }\end{array}$ & $N_{t}$ & $\begin{array}{l}\text { Sumatoria del total de } \\
\text { corrientes de todos los } \\
\text { órdenes que conforman la } \\
\text { red de drenaje }\end{array}$ & - \\
\hline & 12. Orden de la cuenca & $u$ & $\begin{array}{l}\text { Se corresponde con el } \\
\text { número de orden del } \\
\text { segmento de corriente de } \\
\text { orden mayor }\end{array}$ & - \\
\hline & 13. Relación de bifurcación & $R_{b}$ & $R_{b}=\frac{N_{u}}{N_{u+1}}$ & - \\
\hline & $\begin{array}{l}\text { 14. Relación de bifurcación } \\
\text { media }\end{array}$ & $R_{b m}$ & $\begin{array}{l}\text { Se obtiene de la ecuación } \\
\text { exponencial generada de } \\
\text { representar gráficamente el } \\
\text { número de corrientes de un } \\
\text { orden dado contra el orden } \\
\text { de la corriente }\end{array}$ & - \\
\hline & $\begin{array}{l}\text { 15. Longitud de la corriente de } \\
\text { un orden dado }\end{array}$ & $L_{u}$ & $\begin{array}{l}\text { Se miden sobre el plano } \\
\text { (curvímetro o SIG) }\end{array}$ & $\mathrm{km}$ \\
\hline
\end{tabular}




\begin{tabular}{|c|c|c|c|c|}
\hline Variable & Parámetro & Símbolo & Expresión & Unidades \\
\hline \multirow{12}{*}{$\begin{array}{l}\text { Orden y } \\
\text { magnitud } \\
\text { de la red de } \\
\text { drenaje }\end{array}$} & $\begin{array}{l}\text { 1. Longitud total de las } \\
\text { corrientes de un orden dado }\end{array}$ & $L_{t u}$ & $L_{t u}=\sum L_{u}$ & $\mathrm{~km}$ \\
\hline & $\begin{array}{l}\text { 2. Longitud media de las } \\
\text { corrientes de un orden dado }\end{array}$ & $L_{m u}$ & $L_{m u}=\frac{L_{u}}{N_{u}}$ & $\mathrm{~km}$ \\
\hline & $\begin{array}{l}\text { 3. Longitud media acumulada } \\
\text { de las corrientes de un } \\
\text { orden dado }\end{array}$ & $L_{\text {mau }}$ & $L_{m a u}=L_{m u}+L_{m u+1}$ & $\mathrm{~km}$ \\
\hline & 4. Relación de longitud & $R_{L}$ & $R_{L}=\frac{L_{m u}}{L_{m u-1}}$ & - \\
\hline & 5. Relación de longitud media & $R_{L m}$ & $\begin{array}{l}\text { Se obtiene de la ecuación } \\
\text { exponencial generada de } \\
\text { representar gráficamente la } \\
\text { longitud media acumulada } \\
\text { de las corrientes de un } \\
\text { orden dado contra el orden } \\
\text { de la corriente }\end{array}$ & - \\
\hline & $\begin{array}{l}\text { 6. Desnivel de la corriente de } \\
\text { un orden dado }\end{array}$ & $D_{u}$ & $\begin{array}{l}\quad D_{u}=H_{\text {máx }}+h_{\text {min }} \\
\mathrm{H}_{\text {mix }}=\text { altitud máxima del segmento de } \\
\text { corriente } \\
\mathrm{h}_{\min }=\text { altitud mínima del segmento de } \\
\text { corriente }\end{array}$ & $\mathrm{m}$ \\
\hline & $\begin{array}{l}\text { 7. Pendiente de la corriente de } \\
\text { un orden dado }\end{array}$ & $P_{u}$ & $P_{u}=\frac{D_{u}}{L_{u}}$ & $\mathrm{~m} / \mathrm{mo} \%$ \\
\hline & $\begin{array}{l}\text { 8. Desnivel medio de las } \\
\text { corrientes de un orden dado }\end{array}$ & $D_{m u}$ & $D_{m u}=\frac{\sum D_{u}}{N_{u}}$ & $\mathrm{~m}$ \\
\hline & $\begin{array}{l}\text { 9. Pendiente media de las } \\
\text { corrientes de un orden dado }\end{array}$ & $P_{m u}$ & $P_{m u}=\frac{D_{m u}}{L_{m u}}$ & $\mathrm{~m} / \mathrm{mo} \%$ \\
\hline & $\begin{array}{l}\text { 10. Pendiente media acumulada } \\
\text { de las corrientes de un } \\
\text { orden dado }\end{array}$ & $P_{\text {mau }}$ & $P_{m a u}=P_{m u}+P_{m u-1}$ & $\mathrm{~m} / \mathrm{mo} \%$ \\
\hline & 11. Relación de pendiente & $R_{P}$ & $R_{P}=\frac{P_{m u}}{P_{m u-1}}$ & - \\
\hline & $\begin{array}{l}\text { 12. Relación de pendiente } \\
\text { media }\end{array}$ & $R_{p m}$ & $\begin{array}{l}\text { Se obtiene de la ecuación } \\
\text { exponencial generada de } \\
\text { representar gráficamente } \\
\text { la pendiente media de las } \\
\text { corrientes de un orden dado } \\
\text { contra el orden de la corriente }\end{array}$ & - \\
\hline
\end{tabular}




\begin{tabular}{|c|c|c|c|c|}
\hline Variable & Parámetro & Símbolo & Expresión & Unidades \\
\hline \multirow{6}{*}{$\begin{array}{l}\text { Orden y } \\
\text { magnitud } \\
\text { de la red de } \\
\text { drenaje }\end{array}$} & $\begin{array}{l}\text { 1. Frecuencia de las corrientes } \\
\text { de un orden dado }\end{array}$ & $F_{u}$ & $F_{u}=\frac{N_{u}}{A}$ & $\mathrm{~N}_{\mathrm{u}} / \mathrm{km}^{2}$ \\
\hline & $\begin{array}{l}\text { 2. Frecuencia media de las } \\
\text { corrientes totales de la red } \\
\text { de drenaje }\end{array}$ & $F_{m c}$ & $F_{m}=\frac{N_{t}}{A}$ & $\mathrm{~N}_{\mathrm{t}} / \mathrm{km}^{2}$ \\
\hline & $\begin{array}{l}\text { 3. Número de corrientes de } \\
\text { orden } 1\end{array}$ & $N_{1}$ & $\begin{array}{l}\text { Número total de corrientes } \\
\text { de orden } 1 \text { de la red de } \\
\text { drenaje }\end{array}$ & - \\
\hline & $\begin{array}{l}\text { 4. Coeficiente de } \\
\text { torrencialidad }\end{array}$ & $C t$ & $C t=\frac{N_{1}}{A}$ & $\mathrm{~N}_{1} / \mathrm{km}^{2}$ \\
\hline & $\begin{array}{l}\text { 5. Coeficiente de } \\
\text { almacenamiento }\end{array}$ & Ca & $C a=\frac{R_{L}}{R_{b}}$ & - \\
\hline & 6. Magnitud de la cuenca & $M$ & $\begin{array}{l}\text { Número total de corrientes } \\
\text { de primer orden }\end{array}$ & - \\
\hline $\begin{array}{l}\text { Parámetro } \\
\text { hidráulico }\end{array}$ & $\begin{array}{l}\text { 7. Ancho máximo de la } \\
\text { sección hidráulica de interés }\end{array}$ & $a s h_{\text {máx }}$ & $\begin{array}{l}\text { Se mide sobre fotografías } \\
\text { aéreas con una regla }\end{array}$ & $\mathrm{m}$ \\
\hline
\end{tabular}

${ }^{\mathrm{a}} \mathrm{msnm}=$ metros sobre el nivel del mar.

Los valores de las relaciones de bifurcación media, longitud media y pendiente media, fueron estimados a partir de las ecuaciones exponenciales arrojadas por el sistema (Microsoft Excel), como producto de la representación gráfica (gráficos semi-logarítmicos) de las relaciones entre el orden de las corrientes de la red de drenaje (eje x), y el número de corrientes de los distintos órdenes de la red de drenaje (relación de bifurcación), las longitudes medias acumuladas de las corrientes de los órdenes de la red de drenaje (relación de longitud), y las pendientes medias de las corrientes de los órdenes de la red de drenaje (relación de pendiente) (ejes y).

Los anchos máximos de las secciones transversales de los cauces de las quebradas y ríos principales en los ápices de sus abanicos, fueron medidos sobre fotografías aéreas a escala 1:5.000 de la misión 030602 (INSTITUTO GEOGRÁFICO DE VENEZUELA “SIMÓN BOLÍVAR” [IGVSB], 1999-2000). Se realizó un análisis descriptivo de los datos de los parámetros morfométricos, cuyos estadísticos fueron estimados con el complemento Xlstat (2012) de Microsoft Excel.

\section{Resultados}

\section{Escala de la Cuenca}

Las magnitudes medidas para los parámetros de esta variable cuyas estimaciones están vinculadas preci- samente con la escala de la base cartográfica utilizada, en conjunto denotan sistemas hidrogeomorfológicos de pequeñas dimensiones (Tabla 2). Las vertientes con áreas planimétricas mayor y menor de cada cuenca denotan para algunos casos distintivos (cuencas de las quebradas Piedra Azul y San Julián y de los ríos San José de Galipán, Cerro Grande, Naiguatá y Camurí Grande) sistemas con asimetrías muy marcadas. Otras tienden más bien a ser ligeramente asimétricas o ligeramente simétricas, como es el caso de las quebradas Curucutí, Osorio, Cariaco, El Cojo, Camurí Chiquito y Seca y del río Uria.

Además del área, los valores de ancho promedio, ancho máximo y longitud de las cuencas (Tabla 2) también sugieren pequeños sistemas de drenaje con mayor tendencia al crecimiento longitudinal que lateral. Los valores de diámetro y perímetro de las cuencas también corroboran las pequeñas dimensiones de estos sistemas. Con relación a las áreas de los rectángulos equivalentes a los de las cuencas, éstos presentan valores significativamente superiores a los de las áreas naturales de las cuencas, con lo cual se afirma que los trazados de las divisorias de aguas de estos sistemas son muy irregulares y recortados. Esto se verifica de igual manera cuando observamos los valores de los perímetros de los círculos iguales a las áreas de las cuencas (Tabla 2), los cuales son significativamente menores a los perímetros naturales de estos sistemas. 


\section{Gradiente y Forma del Relieve de la Cuenca}

Como ya se ha afirmado, las cuencas de drenaje del sector de estudio están emplazadas sobre la vertiente norte del macizo "El Ávila", cuyas extensiones se comparten en mayor proporción sobre el relieve montañoso, y en menor sobre la franja costera definida por los depósitos aluvionales de los abanicos. Las aguas de estos sistemas drenan directamente al mar Caribe, por lo que se les definen como exorreicos (Figura 2).

Las altitudes en el área (cuencas de recepción) están comprendidas entre $25 \mathrm{msnm}$ (altitud mínima) que corresponde a la cota mínima en la que desembocan algunos de los ríos y quebradas en el frente de montaña, y $2.770 \mathrm{msnm}$ (altitud máxima) correspondiente al punto topográfico más alto para todo el sector representado por el pico Naiguatá, ubicado en el perímetro de la cuenca del río Cerro Grande (Figura 3). Las altitudes mínimas comprenden un rango entre $25 \mathrm{msnm}$ y 125 msnm y las máximas entre $1.280 \mathrm{msnm}$ y $2.770 \mathrm{msnm}$, con promedios de 48,85 msnm y $2.122,08 \mathrm{msnm}$ respectivamente. Por su parte, las altitudes medias oscilan entre $547,71 \mathrm{msnm}$ y $1.316,76 \mathrm{msnm}$ con un promedio de 939,70 msnm (Tabla 2), valores que evidentemente acusan un relieve bastante accidentado, tratándose de sistemas hidrogeomorfológicos de pequeñas dimensiones. Los marcados desniveles altimétricos definen relieves máximos de magnitudes importantes, lo cual es de esperarse en sistemas desarrollados en una vertiente montañosa, dichos valores se encuentran entre $1.230 \mathrm{~m}$ y $2.745 \mathrm{~m}$ con un promedio de $2.073,23 \mathrm{~m}$ (relieves máximos entre medianos y altos). Los radios de relieve son muy acusados también, representando altos desniveles promedios del relieve por unidad de longitud de la cuenca; sus valores están entre 270,83 $\mathrm{m} / \mathrm{km}$ y $442,50 \mathrm{~m} / \mathrm{km}$ con un promedio de $353,45 \mathrm{~m} /$ km (Tabla 2).

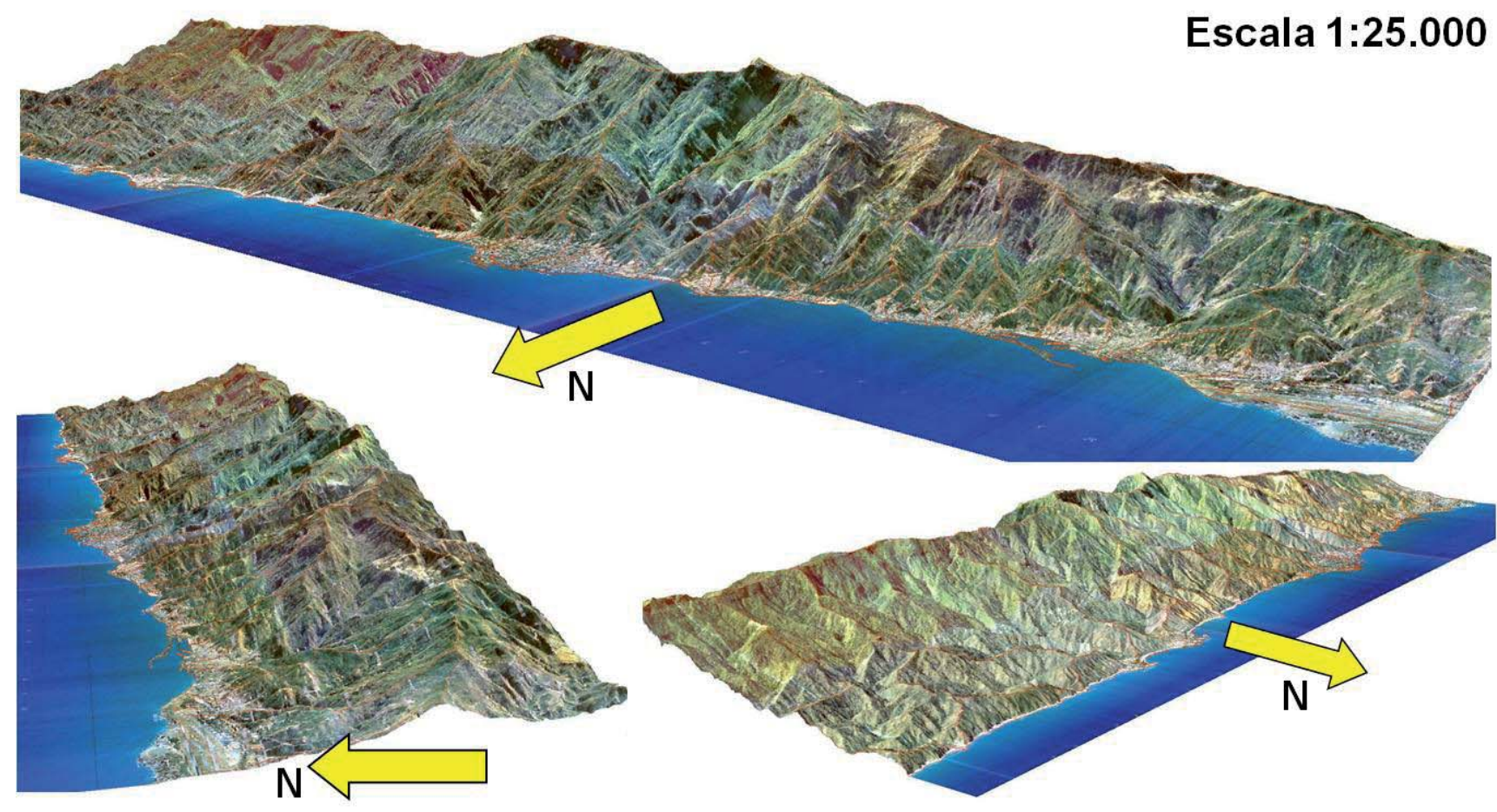

Figura 2 - Modelo en 3D (Modelo de Elevación Digital del Terreno) del relieve de la vertiente norte del macizo "El Ávila”, estado Vargas, Venezuela. MEDT elaborado con base cartográfica tomada de las Hojas “Maiquetía” (6847-IV-NO), “El Caribe” (6847-IV-NE), ”Naiguatá” (6847-I-NO), “23 de Enero” (6847-IV-SO), “Los Chorros” (6847-IV-SE) y “Curupao” (6847-I-SO) a escala 1:25.000 por Dirección de Cartografía Nacional [DCN], 1979, Caracas; y ortofotomapas tomados de las Hojas “Caraballeda” (6847-IV-NE), "Caracas” (6847-IVSO), “Curupao” (6847-I-SO), “La Guaira” (6847-IV-NO), “Los Chorros” (6847-IV-SE) y ”Naiguatá” (6847-I-NO) a escala 1:25.000 por Servicio Autónomo de Geografía y Cartografía Nacional [SAGECAN], 1995, Caracas. 


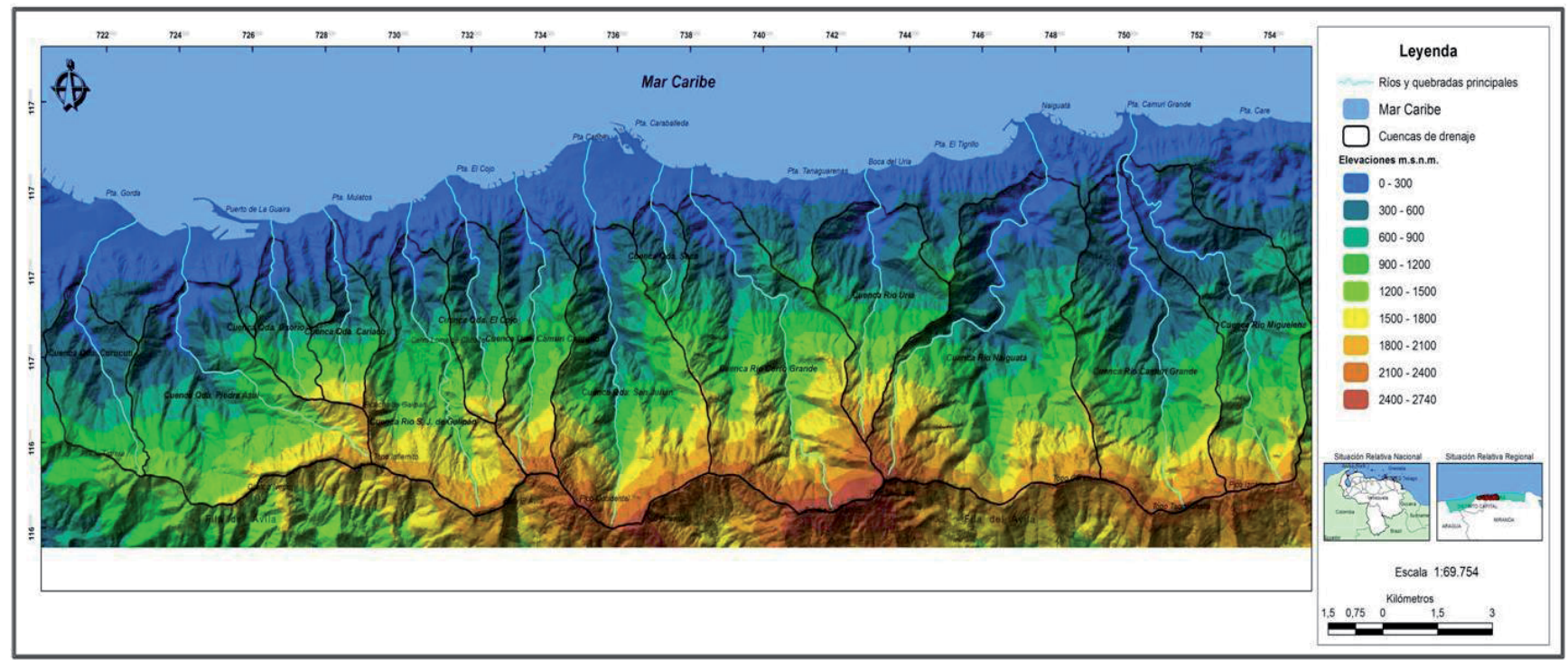

Figura 3 - Hipsometría de cuencas de drenaje de la vertiente norte del macizo "El Ávila”, estado Vargas, Venezuela. Figura y MEDT elaborados con base cartográfica tomada de las Hojas "Maiquetía” (6847-IV-NO), “El Caribe” (6847-IV-NE), "Naiguatá" (6847-I-NO), “23 de Enero” (6847-IVSO), “Los Chorros” (6847-IV-SE) y “Curupao” (6847-I-SO) a escala 1:25.000 por Dirección de Cartografía Nacional [DCN], 1979, Caracas.

Tabla 2: Parámetros morfométricos de cuencas de drenaje de la vertiente norte del macizo “El Ávila”, estado Vargas, Venezuela.

\begin{tabular}{|c|c|c|c|c|c|c|c|c|c|c|}
\hline Cuenca & $\begin{array}{c}\mathrm{A} \\
\left(\mathrm{km}^{2}\right)\end{array}$ & $\begin{array}{l}\mathrm{Va}_{\text {may }} \\
\left(\mathrm{km}^{2}\right)\end{array}$ & $\begin{array}{l}V_{\text {men }} \\
\left(\mathrm{km}^{2}\right)\end{array}$ & $\begin{array}{c}\mathrm{P} \\
(\mathrm{km})\end{array}$ & $\begin{array}{c}\mathrm{L} \\
(\mathrm{km})\end{array}$ & $\begin{array}{c}\mathrm{a} \\
(\mathrm{km})\end{array}$ & $\begin{array}{c}\mathrm{a}_{\text {máx }} \\
(\mathrm{km})\end{array}$ & $\begin{array}{c}\mathrm{D} \\
(\mathrm{km})\end{array}$ & $\begin{array}{c}\mathrm{Ar} \\
\left(\mathrm{km}^{2}\right)\end{array}$ & $\begin{array}{c}\mathrm{Pc} \\
(\mathrm{km})\end{array}$ \\
\hline Qda. Curucutí & 7,34 & 5,12 & 2,22 & 12,20 & 4,80 & 1,53 & 2,63 & 3,06 & 12,62 & 9,60 \\
\hline Qda. Piedra Azul & 20,22 & 15,60 & 4,62 & 20,50 & 6,65 & 3,04 & 4,40 & 5,07 & 29,26 & 15,94 \\
\hline Qda. Osorio & 4,04 & 2,43 & 1,61 & 9,90 & 4,00 & 1,01 & 1,68 & 2,27 & 6,72 & 7,13 \\
\hline Qda. Cariaco & 4,58 & 2,36 & 2,22 & 10,90 & 4,45 & 1,03 & 2,03 & 2,41 & 9,03 & 7,59 \\
\hline Río San José de Galipán & 14,56 & 10,07 & 4,49 & 18,20 & 6,88 & 2,12 & 3,05 & 4,31 & 20,98 & 13,53 \\
\hline Qda. El Cojo & 5,78 & 2,90 & 2,88 & 10,90 & 4,75 & 1,22 & 1,58 & 2,71 & 7,51 & 8,52 \\
\hline Qda. Camurí Chiquito & 9,39 & 4,97 & 4,42 & 15,50 & 6,38 & 1,47 & 2,18 & 3,46 & 13,91 & 10,86 \\
\hline Qda. San Julián & 20,68 & 12,10 & 8,58 & 19,60 & 7,45 & 2,78 & 4,33 & 5,13 & 32,26 & 16,12 \\
\hline Qda. Seca & 2,89 & 1,63 & 1,26 & 6,80 & 2,88 & 1,00 & 1,40 & 1,92 & 4,03 & 6,03 \\
\hline Río Cerro Grande & 25,38 & 16,55 & 8,83 & 22,50 & 8,70 & 2,92 & 4,93 & 5,68 & 42,89 & 17,86 \\
\hline Río Uria & 11,57 & 6,53 & 5,04 & 16,20 & 5,55 & 2,08 & 3,75 & 3,84 & 20,81 & 12,06 \\
\hline Río Naiguatá & 31,38 & 25,55 & 5,83 & 25,10 & 8,38 & 3,74 & 6,18 & 6,32 & 51,79 & 19,86 \\
\hline Río Camurí Grande & 22,74 & 14,23 & 8,51 & 21,60 & 8,13 & 2,80 & 4,28 & 5,38 & 34,80 & 16,90 \\
\hline Valor máximo $=$ & 31,38 & 25,55 & 8,83 & 25,10 & 8,70 & 3,74 & 6,18 & 6,32 & 51,79 & 19,86 \\
\hline Valor mínimo = & 2,89 & 1,63 & 1,26 & 6,80 & 2,88 & 1,00 & 1,40 & 1,92 & 4,03 & 6,03 \\
\hline Media $=$ & 13,89 & 9,23 & 4,65 & 16,15 & 6,08 & 2,06 & 3,26 & 3,97 & 22,05 & 12,46 \\
\hline Moda $=$ & - & - & 2,22 & 10,90 & - & - & - & - & - & - \\
\hline Mediana $=$ & 11,57 & 6,53 & 4,49 & 16,20 & 6,38 & 2,08 & 3,05 & 3,84 & 20,81 & 12,06 \\
\hline Varianza $=$ & 86,82 & 52,34 & 7,09 & 31,90 & 3,35 & 0,85 & 2,24 & 2,11 & 227,99 & 20,85 \\
\hline Desviación estándar $=$ & 9,32 & 7,23 & 2,66 & 5,65 & 1,83 & 0,92 & 1,50 & 1,45 & 15,10 & 4,57 \\
\hline Asimetría $=$ & 0,50 & 0,95 & 0,47 & $-0,08$ & $-0,13$ & 0,36 & 0,43 & 0,12 & 0,65 & 0,12 \\
\hline Curtosis $=$ & $-1,02$ & 0,41 & $-1,01$ & $-1,17$ & $-1,06$ & $-1,18$ & $-0,80$ & $-1,40$ & $-0,59$ & $-1,40$ \\
\hline Coeficiente de variación $=$ & 0,67 & 0,78 & 0,57 & 0,35 & 0,30 & 0,45 & 0,46 & 0,37 & 0,68 & 0,37 \\
\hline Primer cuartil $=$ & 5,78 & 2,90 & 2,22 & 10,90 & 4,75 & 1,22 & 2,03 & 2,71 & 9,03 & 8,52 \\
\hline Segundo cuartil $=$ & 11,57 & 6,53 & 4,49 & 16,20 & 6,38 & 2,08 & 3,05 & 3,84 & 20,81 & 12,06 \\
\hline Tercer cuartil $=$ & 20,68 & 14,23 & 5,83 & 20,50 & 7,45 & 2,80 & 4,33 & 5,13 & 32,26 & 16,12 \\
\hline
\end{tabular}

$A=$ área; Vamay= Vertiente con mayor área; Vamen= Vertiente con menor área; $P=$ perímetro; $L=$ longitud; $a=$ ancho promedio; amá $x=$ ancho máximo; $D$ = diámetro; $A r=$ área del rectángulo equivalente al de la cuenca; $P c=$ perímetro de un círculo igual al área de la cuenca. 


\begin{tabular}{|c|c|c|c|c|c|c|c|c|c|c|}
\hline Cuenca & $\begin{array}{c}\mathrm{h} \\
(\mathrm{msnm})\end{array}$ & $\begin{array}{c}\mathrm{H} \\
(\mathrm{msnm})\end{array}$ & $\begin{array}{c}\mathrm{Hm} \\
(\mathrm{msnm})\end{array}$ & $\underset{(m s n m)}{\mathrm{H}_{\mathrm{n}}}$ & $\begin{array}{c}\mathrm{h}_{\mathrm{d}} \\
(\mathrm{msnm})\end{array}$ & $\begin{array}{l}\mathrm{Rm} \\
(\mathrm{m})\end{array}$ & $\begin{array}{c}\mathrm{R} \\
(\mathrm{m} / \mathrm{km})\end{array}$ & \begin{tabular}{|c|}
$\mathrm{P}_{\mathrm{m}}$ \\
$(\mathrm{m} / \mathrm{m})$
\end{tabular} & $\mathrm{Cp}$ & $\begin{array}{l}\mathrm{Pcp}_{\mathrm{m}} \\
(\mathrm{m} / \mathrm{m})\end{array}$ \\
\hline Qda. Curucutí & 125 & 1425 & 634,26 & 1400 & 125 & 1300 & 270,83 & 0,24 & 0,47 & 0,27 \\
\hline Qda. Piedra Azul & 60 & 1950 & 992,70 & 1900 & 60 & 1890 & 284,21 & 0,27 & 0,04 & 0,22 \\
\hline Qda. Osorio & 25 & 1795 & 790,10 & 1770 & 25 & 1770 & 442,50 & 0,31 & 0,32 & 0,36 \\
\hline Qda. Cariaco & 25 & 1975 & 792,52 & 1925 & 25 & 1950 & 438,20 & 0,32 & 0,56 & 0,41 \\
\hline Río San José de Galipán & 25 & 2290 & 1275,16 & 2220 & 25 & 2265 & 329,22 & 0,29 & 0,00 & 0,21 \\
\hline Qda. El Cojo & 50 & 1925 & 785,33 & 1890 & 50 & 1875 & 394,74 & 0,33 & 0,61 & 0,25 \\
\hline Qda. Camurí Chiquito & 50 & 2370 & 1003,64 & 2300 & 50 & 2320 & 363,64 & 0,29 & 0,38 & 0,28 \\
\hline Qda. San Julián & 105 & 2640 & 1247,66 & 2305 & 105 & 2535 & 340,27 & 0,34 & 0,58 & 0,22 \\
\hline Qda. Seca & 50 & 1280 & 547,71 & 1200 & 50 & 1230 & 427,08 & 0,27 & 0,39 & 0,34 \\
\hline Río Cerro Grande & 25 & 2770 & 1316,76 & 2550 & 25 & 2745 & 315,52 & 0,31 & 0,13 & 0,21 \\
\hline Río Uria & 40 & 2282 & 827,72 & 2275 & 40 & 2242 & 403,96 & 0,29 & 0,17 & 0,37 \\
\hline Río Naiguatá & 25 & 2585 & 1090,00 & 2525 & 2. & 2560 & 305,49 & 0,30 & 0,68 & 0,21 \\
\hline Río Camurí Grande & 30 & 2300 & 912,55 & 2265 & 30 & 2270 & 279,21 & 0,28 & 0,71 & 0,20 \\
\hline Valor máximo = & 125 & 2770 & 1316,76 & 2550 & 125 & 2745 & 442,50 & 0,34 & 0,71 & 0,41 \\
\hline Valor mínimo $=$ & 25 & 1280 & 547,71 & 1200 & 25 & 1230 & 270,83 & 0,24 & 0,00 & 0,20 \\
\hline Media $=$ & 48,85 & 2122,08 & 939,70 & 2040,38 & 48,85 & 2073,23 & 353,45 & 0,30 & 0,39 & 0,27 \\
\hline Moda $=$ & 25 & - & - & - & 25 & - & - & - & - & - \\
\hline Mediana $=$ & 40 & 2282 & 912,55 & 2220,00 & 40 & 2242 & 340,27 & 0,29 & 0,39 & 0,25 \\
\hline Varianza $=$ & 1029,81 & 203442,74 & 58927,74 & 167901,92 & 1029,81 & 212937,36 & 3877,14 & 0,0007 & 0,06 & 0,01 \\
\hline Desviación estándar = & 32,09 & 451,05 & 242,75 & 409,76 & 32,09 & 461,45 & 62,27 & 0,03 & 0,24 & 0,07 \\
\hline Asimetría $=$ & 1,62 & $-0,48$ & 0,17 & $-0,82$ & 1,62 & $-0,56$ & 0,17 & $-0,33$ & $-0,32$ & 0,76 \\
\hline Curtosis $=$ & 1,97 & $-0,42$ & $-0,89$ & 0,04 & 1,97 & $-0,32$ & $-1,53$ & 0,40 & $-1,24$ & $-0,92$ \\
\hline Coeficiente de variación $=$ & 0,66 & 0,21 & 0,26 & 0,20 & 0,66 & 0,22 & 0,18 & 0,09 & 0,62 & 0,27 \\
\hline Primer cuartil $=$ & 25 & 1925 & 790,10 & 1890 & 25 & 1875 & 305,49 & 0,28 & 0,17 & 0,21 \\
\hline Segundo cuartil $=$ & 40 & 2282 & 912,55 & 2220 & 40 & 2242 & 340,27 & 0,29 & 0,39 & 0,25 \\
\hline Tercer cuartil $=$ & 50 & 2370 & 1090 & 2300 & 50 & 2320 & 403,96 & 0,31 & 0,58 & 0,34 \\
\hline
\end{tabular}

$h=$ altitud mínima; $H=$ altitud máxima; $H$ m = altitud media; $H_{n}=$ altitud de la naciente de la corriente principal; $h_{d}=$ Altitud del desagüe de la corriente principal; $R m=$ relieve máximo; $R=$ radio del relieve; $P_{m}=$ pendiente media del relieve; $C p=$ Concavidad del perfil longitudinal de la corriente principal; $P \mathrm{Cp}_{\mathrm{m}}=$ Pendiente media del perfil longitudinal de la corriente principal.

\begin{tabular}{|l|c|c|c|c|cc|c|c|c|c|c|}
\hline \multicolumn{1}{|c|}{ Cuenca } & $\begin{array}{c}\mathrm{Rmcp} \\
(\mathrm{m})\end{array}$ & $\mathrm{Ft}$ & $\begin{array}{c}\mathrm{Ptc}_{\mathrm{m}} \\
(\mathrm{m} / \mathrm{m})\end{array}$ & $\mathrm{IH}$ & $\begin{array}{c}\mathrm{Cm} \\
\left(\mathrm{msnm} / \mathrm{km}^{2}\right)\end{array}$ & $\mathrm{Co}$ & $\begin{array}{c}\mathrm{Rr} \\
(\mathrm{m} / \mathrm{km})\end{array}$ & $\mathrm{NR}$ & $\mathrm{E}$ & $\operatorname{Prc}$ \\
\hline Qda. Curucutí & 1275 & 666,30 & 0,52 & 0,39 & 86,41 & 54807,84 & 106,56 & 0,48 & 0,56 & 20,28 \\
Qda. Piedra Azul & 1840 & 862,45 & 0,50 & 0,49 & 49,09 & 48736,40 & 92,20 & 0,42 & 0,68 & 20,78 \\
Qda. Osorio & 1745 & 1047,87 & 0,66 & 0,43 & 195,57 & 154518,28 & 178,79 & 0,88 & 0,50 & 24,26 \\
Qda. Cariaco & 1900 & 1218,82 & 0,68 & 0,39 & 173,04 & 137138,05 & 178,90 & 0,91 & 0,48 & 25,94 \\
Río San José de & 2195 & 1007,31 & 0,82 & 0,55 & 87,58 & 111678,53 & 124,45 & 0,59 & 0,55 & 22,75 \\
Galipán & 1840 & 925,50 & 0,71 & 0,39 & 135,87 & 106702,13 & 172,02 & 0,78 & 0,51 & 20,56 \\
Qda. El Cojo & 2250 & 1184,19 & 0,71 & 0,41 & 106,88 & 107273,61 & 149,68 & 0,76 & 0,48 & 25,59 \\
Qda. Camurí Chiquito & 2200 & 1025,78 & 0,69 & 0,45 & 60,33 & 75273,59 & 129,34 & 0,56 & 0,61 & 18,58 \\
Qda. San Julián & 1150 & 667,89 & 0,64 & 0,40 & 189,52 & 103801,57 & 180,88 & 0,72 & 0,59 & 16,00 \\
Qda. Seca & 2525 & 1162,60 & 0,64 & 0,47 & 51,88 & 68315,56 & 122,00 & 0,54 & 0,58 & 19,95 \\
Río Cerro Grande & 2235 & 1367,37 & 0,58 & 0,35 & 71,54 & 59215,53 & 138,40 & 0,66 & 0,61 & 22,68 \\
Río Uria & 2500 & 1131,92 & 0,61 & 0,42 & 34,74 & 37861,90 & 101,99 & 0,46 & 0,67 & 20,08 \\
Río Naiguatá & 2235 & 995,01 & 0,65 & 0,39 & 40,13 & 36620,01 & 105,09 & 0,48 & 0,59 & 20,52
\end{tabular}


Méndez Mata W. J. et al.

\begin{tabular}{|lcccccccccc|} 
Valor máximo = & 2525 & 1367,37 & 0,82 & 0,55 & 195,57 & 154518,28 & 180,88 & 0,91 & 0,68 & 25,94 \\
Valor mínimo = & 1150 & 666,30 & 0,50 & 0,35 & 34,74 & 36620,01 & 92,20 & 0,42 & 0,48 & 16,00 \\
Media $=$ & 1991,54 & 1020,23 & 0,65 & 0,43 & 98,66 & 84764,85 & 136,94 & 0,63 & 0,57 & 21,38 \\
Moda $=$ & 1840 & - & - & - & - & - & - & - & - & - \\
Mediana $=$ & 2195 & 1025,78 & 0,65 & 0,41 & 86,41 & 75273,59 & 129,34 & 0,59 & 0,58 & 20,56 \\
Varianza $=$ & 179168,27 & 42037,25 & 0,01 & 0,00 & 3272,13 & 1450819954 & 1036,28 & 0,03 & 0,00 & 7,83 \\
Desviación estándar = & 423,28 & 205,03 & 0,08 & 0,05 & 57,20 & 38089,63 & 32,19 & 0,16 & 0,06 & 2,80 \\
Asimetría = & $-0,83$ & $-0,39$ & 0,15 & 1,12 & 0,71 & 0,39 & 0,23 & 0,40 & 0,10 & 0,05 \\
Curtosis = & 0,08 & $-0,09$ & 0,81 & 1,32 & $-0,95$ & $-0,94$ & $-1,50$ & $-1,14$ & $-0,82$ & $-0,03$ \\
Coeficiente de variación $=$ & 0,21 & 0,20 & 0,13 & 0,12 & 0,58 & 0,45 & 0,24 & 0,26 & 0,11 & 0,13 \\
Primer cuartil = & 1840 & 925,50 & 0,61 & 0,39 & 51,88 & 54807,84 & 106,56 & 0,48 & 0,51 & 20,08 \\
Segundo cuartil = & 2195 & 1025,78 & 0,65 & 0,41 & 86,41 & 75273,59 & 129,34 & 0,59 & 0,58 & 20,56 \\
Tercer cuartil = & 2235 & 1162,60 & 0,69 & 0,45 & 135,87 & 107273,61 & 172,02 & 0,76 & 0,61 & 22,75 \\
\hline
\end{tabular}

$R m c p=$ relieve máximo de la corriente principal; $\mathrm{Ft}=$ factor topográfico de la corriente principal; Ptc $_{m}=$ Pendiente media del total de corrientes de la red de drenaje; $I H=$ integral hipsométrica; $\mathrm{Cm}=$ coeficiente de masividad; $\mathrm{Co}=$ coeficiente orográfico; $\mathrm{Rr}=$ relieve relativo; $N R=$ número de rugosidad de Melton; $E=$ elongación; Prc= perímetro relativo de crenulación.

\begin{tabular}{|c|c|c|c|c|c|c|c|c|c|c|}
\hline Cuenca & Kc & Ia & Ih & Is & Ff & Ac & $\operatorname{Re}$ & $\mathrm{RC}$ & If & $\mathrm{ICo}$ \\
\hline Qda. Curucutí & 1,26 & 1,83 & 0,58 & 2,31 & 0,32 & 1,77 & 0,64 & 0,62 & 1,80 & 1,13 \\
\hline Qda. Piedra Azul & 1,28 & 1,51 & 0,69 & 3,38 & 0,46 & 1,48 & 0,76 & 0,60 & 1,82 & 1,13 \\
\hline Qda. Osorio & 1,38 & 2,38 & 0,60 & 1,51 & 0,25 & 1,99 & 0,57 & 0,52 & 1,96 & 1,13 \\
\hline Qda. Cariaco & 1,43 & 2,19 & 0,51 & 1,06 & 0,23 & 2,08 & 0,54 & 0,48 & 2,03 & 1,13 \\
\hline Río San José de Galipán & 1,34 & 2,26 & 0,69 & 2,24 & 0,31 & 1,80 & 0,63 & 0,55 & 1,90 & 1,13 \\
\hline Qda. El Cojo & 1,27 & 3,01 & 0,77 & 1,01 & 0,26 & 1,98 & 0,57 & 0,61 & 1,81 & 1,13 \\
\hline Qda. Camurí Chiquito & 1,42 & 2,93 & 0,68 & 1,12 & 0,23 & 2,08 & 0,54 & 0,49 & 2,02 & 1,13 \\
\hline Qda. San Julián & 1,21 & 1,72 & 0,64 & 1,41 & 0,37 & 1,64 & 0,69 & 0,68 & 1,72 & 1,13 \\
\hline Qda. Seca & 1,12 & 2,06 & 0,72 & 1,29 & 0,35 & 1,69 & 0,67 & 0,79 & 1,60 & 1,13 \\
\hline Río Cerro Grande & 1,25 & 1,76 & 0,59 & 1,87 & 0,34 & 1,73 & 0,65 & 0,63 & 1,78 & 1,13 \\
\hline Río Uria & 1,33 & 1,48 & 0,56 & 1,30 & 0,38 & 1,63 & 0,69 & 0,55 & 1,90 & 1,13 \\
\hline Río Naiguatá & 1,25 & 1,36 & 0,61 & 4,38 & 0,45 & 1,50 & 0,75 & 0,63 & 1,79 & 1,13 \\
\hline Río Camurí Grande & 1,27 & 1,90 & 0,65 & 1,67 & 0,34 & 1,70 & 0,66 & 0,61 & 1,81 & 1,13 \\
\hline Valor máximo = & 1,43 & 3,01 & 0,77 & 4,38 & 0,46 & 2,08 & 0,76 & 0,79 & 2,03 & 1,13 \\
\hline Valor mínimo = & 1,12 & 1,36 & 0,51 & 1,01 & 0,23 & 1,48 & 0,54 & 0,48 & 1,60 & 1,13 \\
\hline Media $=$ & 1,29 & 2,03 & 0,64 & 1,89 & 0,33 & 1,77 & 0,64 & 0,60 & 1,84 & 1,13 \\
\hline Moda $=$ & - & - & - & - & - & - & - & - & - & 1,13 \\
\hline Mediana $=$ & 1,27 & 1,90 & 0,64 & 1,51 & 0,34 & 1,73 & 0,65 & 0,61 & 1,81 & 1,13 \\
\hline Varianza $=$ & 0,01 & 0,27 & 0,01 & 0,99 & 0,01 & 0,04 & 0,01 & 0,01 & 0,01 & 0,00 \\
\hline Desviación estándar $=$ & 0,09 & 0,52 & 0,07 & 1,00 & 0,07 & 0,20 & 0,07 & 0,08 & 0,12 & 0,00 \\
\hline Asimetría $=$ & $-0,12$ & 0,75 & 0,04 & 1,66 & 0,29 & 0,25 & 0,10 & 0,72 & $-0,12$ & 4,09 \\
\hline Curtosis $=$ & 0,18 & $-0,14$ & $-0,30$ & 2,43 & $-0,65$ & $-1,00$ & $-0,82$ & 1,29 & 0,18 & 15,93 \\
\hline Coeficiente de variación $=$ & 0,07 & 0,25 & 0,11 & 0,53 & 0,23 & 0,11 & 0,11 & 0,14 & 0,07 & 0,00 \\
\hline Primer cuartil $=$ & 1,25 & 1,72 & 0,59 & 1,29 & 0,26 & 1,64 & 0,57 & 0,55 & 1,79 & 1,13 \\
\hline Segundo cuartil $=$ & 1,27 & 1,90 & 0,64 & 1,51 & 0,34 & 1,73 & 0,65 & 0,61 & 1,81 & 1,13 \\
\hline Tercer cuartil $=$ & 1,34 & 2,26 & 0,69 & 2,24 & 0,37 & 1,98 & 0,69 & 0,63 & 1,90 & 1,13 \\
\hline
\end{tabular}

$K c=$ coeficiente de compacidad; Ia = índice de alargamiento; Ih= índice de homogeneidad; Is= índice de simetría; Ff= factor forma; Ac= alargamiento de Caquot; $R e=$ radio de elongación; $R C=$ radio de circularidad; If= índice de forma; ICo= Índice entre el largo y el área de la cuenca . 


\begin{tabular}{|c|c|c|c|c|c|c|c|c|c|c|}
\hline Cuenca & $\mathrm{Cf}$ & $\mathrm{Cr}$ & $\begin{array}{l}\text { Lcp } \\
(\mathrm{km})\end{array}$ & $\begin{array}{l}\mathrm{Lv}_{\mathrm{m}} \\
(\mathrm{km})\end{array}$ & $\begin{array}{l}\text { Ltc } \\
(\mathrm{km})\end{array}$ & S & St & Sh & $\begin{array}{c}\mathrm{Cg} \\
(\mathrm{km})\end{array}$ & $\begin{array}{c}\mathrm{Dd} \\
\left(\mathrm{km} / \mathrm{km}^{2}\right)\end{array}$ \\
\hline Qda. Curucutí & 0,32 & 2,47 & 5,11 & 4,80 & 59,66 & 1,09 & 1,02 & 1,07 & 2,56 & 8,13 \\
\hline Qda. Piedra Azul & 0,46 & 1,72 & 8,98 & 8,00 & 113,75 & 1,40 & 1,24 & 1,12 & 4,49 & 5,63 \\
\hline Qda. Osorio & 0,25 & 3,11 & 5,47 & 4,00 & 42,54 & 1,45 & 1,06 & 1,37 & 2,74 & 10,53 \\
\hline Qda. Cariaco & 0,23 & 3,40 & 5,25 & 4,30 & 43,29 & 1,24 & 1,02 & 1,22 & 2,63 & 9,45 \\
\hline Río San José de Galipán & 0,31 & 2,55 & 9,29 & 8,00 & 215,11 & 1,41 & 1,22 & 1,16 & 4,65 & 14,77 \\
\hline Qda. El Cojo & 0,26 & 3,07 & 6,73 & 5,10 & 71,97 & 1,46 & 1,11 & 1,32 & 3,37 & 12,45 \\
\hline Qda. Camurí Chiquito & 0,23 & 3,40 & 7,80 & 7,00 & 89,73 & 1,28 & 1,15 & 1,11 & 3,90 & 9,56 \\
\hline Qda. San Julián & 0,37 & 2,11 & 8,30 & 7,50 & 140,49 & 1,14 & 1,03 & 1,11 & 4,15 & 6,79 \\
\hline Qda. Seca & 0,35 & 2,25 & 3,55 & 3,00 & 34,03 & 1,32 & 1,12 & 1,18 & 1,78 & 11,77 \\
\hline Río Cerro Grande & 0,34 & 2,34 & 11,75 & 10,00 & 213,72 & 1,39 & 1,18 & 1,18 & 5,88 & 8,42 \\
\hline Río Uria & 0,38 & 2,09 & 6,96 & 6,00 & 121,05 & 1,31 & 1,13 & 1,16 & 3,48 & 10,46 \\
\hline Río Naiguatá & 0,45 & 1,76 & 13,55 & 11,00 & 255,55 & 1,66 & 1,34 & 1,23 & 6,78 & 8,14 \\
\hline Río Camurí Grande & 0,34 & 2,28 & 9,39 & 9,00 & 202,41 & 1,18 & 1,13 & 1,04 & 4,70 & 8,90 \\
\hline Valor máximo = & 0,46 & 3,40 & 13,55 & 11,00 & 255,55 & 1,66 & 1,34 & 1,37 & 6,78 & 14,77 \\
\hline Valor mínimo $=$ & 0,23 & 1,72 & 3,55 & 3,00 & 34,03 & 1,09 & 1,02 & 1,04 & 1,78 & 5,63 \\
\hline Media $=$ & 0,33 & 2,50 & 7,86 & 6,75 & 123,33 & 1,33 & 1,13 & 1,17 & 3,93 & 9,62 \\
\hline Moda $=$ & - & - & - & 8,00 & - & - & - & - & - & - \\
\hline Mediana $=$ & 0,34 & 2,34 & 7,80 & 7,00 & 113,75 & 1,32 & 1,13 & 1,16 & 3,90 & 9,45 \\
\hline Varianza $=$ & 0,01 & 0,33 & 7,84 & 6,01 & 5787,62 & 0,02 & 0,01 & 0,01 & 1,96 & 5,92 \\
\hline Desviación estándar $=$ & 0,07 & 0,57 & 2,80 & 2,45 & 76,08 & 0,15 & 0,10 & 0,09 & 1,40 & 2,43 \\
\hline Asimetría $=$ & 0,29 & 0,41 & 0,53 & 0,18 & 0,48 & 0,31 & 0,72 & 0,76 & 0,53 & 0,52 \\
\hline Curtosis $=$ & $-0,65$ & $-1,00$ & 0,05 & $-0,94$ & $-1,23$ & 0,36 & 0,41 & 0,31 & 0,05 & 0,49 \\
\hline Coeficiente de variación $=$ & 0,23 & 0,23 & 0,36 & 0,36 & 0,62 & 0,12 & 0,08 & 0,08 & 0,36 & 0,25 \\
\hline Primer cuartil $=$ & 0,26 & 2,11 & 5,47 & 4,80 & 59,66 & 1,24 & 1,06 & 1,11 & 2,74 & 8,14 \\
\hline Segundo cuartil $=$ & 0,34 & 2,34 & 7,80 & 7,00 & 113,75 & 1,32 & 1,13 & 1,16 & 3,90 & 9,45 \\
\hline Tercer cuartil $=$ & 0,37 & 3,07 & 9,29 & 8,00 & 202,41 & 1,41 & 1,18 & 1,22 & 4,65 & 10,53 \\
\hline
\end{tabular}

$C f=$ coeficiente de forma; $C r=$ coeficiente de redondez; $L c p=$ longitud de la corriente principal; $L v_{m}=$ longitud media del valle de la corriente principal; Ltc= longitud total de las corrientes de la red de drenaje; $S=$ sinuosidad total de la corriente principal; St= sinuosidad topográfica de la corriente principal; Sh= sinuosidad hidráulica de la corriente principal; Cg= centro de gravedad del cauce principal; Dd= densidad de drenaje.

\begin{tabular}{|l|c|c|c|c|c|c|c|c|c|c|}
\hline \multicolumn{1}{|c}{ Cuenca } & $\begin{array}{c}\mathrm{Td} \\
\left(\mathrm{km}^{-1}\right)\end{array}$ & $\begin{array}{c}\mathrm{Cmc} \\
\left(\mathrm{km}^{2} / \mathrm{km}\right)\end{array}$ & $\begin{array}{c}\mathrm{Em} \\
(\mathrm{km})\end{array}$ & $\begin{array}{c}\mathrm{Lfs} \\
(\mathrm{km})\end{array}$ & $\mathrm{Tt}$ & $\begin{array}{c}\mathrm{Id} \\
(\mathrm{km})\end{array}$ & $\mathrm{Am}$ & $\mathrm{N}_{\mathrm{t}}$ & $\mathrm{u}$ & $\mathrm{R}_{\mathrm{bm}}$ \\
\hline Qda. Curucutí & 238,08 & 0,12 & 0,03 & 0,06 & 1,23 & 3,60 & 1,89 & 215 & 5 & 3,73 \\
Qda. Piedra Azul & 87,08 & 0,18 & 0,04 & 0,10 & 1,06 & 2,75 & 2,00 & 313 & 5 & 3,90 \\
Qda. Osorio & 440,42 & 0,09 & 0,02 & 0,04 & 1,36 & 3,97 & 2,72 & 169 & 4 & 4,79 \\
Qda. Cariaco & 383,86 & 0,11 & 0,03 & 0,05 & 1,31 & 4,30 & 2,45 & 186 & 5 & 3,58 \\
Río San José de Galipán & 1136,46 & 0,07 & 0,02 & 0,03 & 1,52 & 5,21 & 2,43 & 1120 & 6 & 3,91 \\
Qda. El Cojo & 779,84 & 0,08 & 0,02 & 0,04 & 1,44 & 5,03 & 2,80 & 362 & 5 & 4,37 \\
Qda. Camurí Chiquito & 383,64 & 0,10 & 0,03 & 0,04 & 1,31 & 4,20 & 2,55 & 377 & 5 & 4,12 \\
Qda. San Julián & 149,47 & 0,15 & 0,04 & 0,07 & 1,15 & 3,24 & 1,83 & 455 & 5 & 4,36 \\
Qda. Seca & 692,55 & 0,08 & 0,02 & 0,04 & 1,41 & 5,00 & 2,09 & 170 & 4 & 4,99 \\
Río Cerro Grande & 272,72 & 0,12 & 0,03 & 0,06 & 1,25 & 3,85 & 2,33 & 822 & 6 & 3,78 \\
Río Uria & 461,18 & 0,10 & 0,02 & 0,05 & 1,36 & 4,21 & 2,05 & 510 & 5 & 4,31 \\
Río Naiguatá & 240,84 & 0,12 & 0,03 & 0,06 & 1,24 & 3,63 & 2,42 & 928 & 6 & 3,76 \\
Río Camurí Grande & 329,19 & 0,11 & 0,03 & 0,05 & 1,28 & 4,15 & 1,97 & 841 & 6 & 3,66
\end{tabular}


Méndez Mata W. J. et al.

\begin{tabular}{|lcccccccccc|} 
Valor máximo = & 1136,46 & 0,18 & 0,04 & 0,10 & 1,52 & 5,21 & 2,80 & 1120 & 6 & 4,99 \\
Valor mínimo = & 87,08 & 0,07 & 0,02 & 0,03 & 1,06 & 2,75 & 1,83 & 169 & 4 & 3,58 \\
Media $=$ & 430,41 & 0,11 & 0,03 & 0,05 & 1,30 & 4,09 & 2,27 & 497,54 & 5,15 & 4,10 \\
Moda $=$ & - & - & - & - & - & - & - & - & 5 & - \\
Mediana $=$ & 383,64 & 0,11 & 0,03 & 0,05 & 1,31 & 4,15 & 2,33 & 377 & 5 & 3,91 \\
Varianza = & 83297,75 & 0,0008 & 0,0001 & 0,0003 & 0,02 & 0,51 & 0,10 & 104751,6 & 0,47 & 0,20 \\
Desviación estándar = & 288,61 & 0,03 & 0,01 & 0,02 & 0,12 & 0,71 & 0,32 & 323,65 & 0,69 & 0,44 \\
Asimetría = & 1,36 & 0,92 & 0,92 & 1,18 & $-0,19$ & $-0,06$ & 0,19 & 0,76 & $-0,20$ & 0,84 \\
Curtosis = & 1,87 & 1,28 & 1,28 & 2,39 & 0,32 & $-0,23$ & $-1,27$ & $-0,78$ & $-0,50$ & $-0,21$ \\
Coeficiente de variación & 0,67 & 0,26 & 0,26 & 0,34 & 0,10 & 0,17 & 0,14 & 0,65 & 0,13 & 0,11 \\
P & 240,84 & 0,09 & 0,02 & 0,04 & 1,24 & 3,63 & 2,00 & 215 & 5 & 3,76 \\
Primer cuartil = & 383,64 & 0,11 & 0,03 & 0,05 & 1,31 & 4,15 & 2,33 & 377 & 5 & 3,91 \\
Segundo cuartil = & 38,13 & \\
Tercer cuartil = & 461,18 & 0,12 & 0,03 & 0,06 & 1,36 & 4,30 & 2,45 & 822 & 6 & 4,36 \\
\hline
\end{tabular}

$T d=$ textura del drenaje; $C m c$ = coeficiente de mantenimiento del canal; Em= Extensión media de la escorrentía superficial; Lfs= longitud del flujo superficial; $T t=$ textura topográfica; Id = intensidad de drenaje; $A m=$ alejamiento medio; $N_{t}=$ número total de corrientes de la red de drenaje; $u=$ orden de la cuenca; $R_{b m}=$ relación de bifurcación media.

\begin{tabular}{|l|c|c|c|c|c|c|c|}
\hline \multicolumn{1}{|c|}{ Cuenca } & $\mathrm{R}_{\mathrm{Lm}}$ & $\mathrm{R}_{\mathrm{pm}}$ & $\begin{array}{c}\mathrm{F}_{\mathrm{mc}} \\
\left(\mathrm{N}_{\mathrm{t}} / \mathrm{km}^{2}\right)\end{array}$ & $\begin{array}{c}\mathrm{Ct} \\
\left(\mathrm{N}_{\mathrm{l}} / \mathrm{km}^{2}\right)\end{array}$ & $\mathrm{Ca}$ & $\mathrm{M}$ & $\begin{array}{c}\text { ash }_{\text {máx }} \\
(\mathrm{m})\end{array}$ \\
\hline Qda. Curucutí & 2,17 & 1,42 & 29,29 & 22,34 & 0,58 & 164 & 50 \\
Qda. Piedra Azul & 2,25 & 1,35 & 15,48 & 11,72 & 0,58 & 237 & 50 \\
Qda. Osorio & 2,44 & 1,34 & 41,83 & 31,44 & 0,51 & 127 & 35 \\
Qda. Cariaco & 2,02 & 1,49 & 40,61 & 30,57 & 0,57 & 140 & 40 \\
Río San José de Galipán & 2,14 & 1,28 & 76,92 & 60,85 & 0,55 & 886 & 50 \\
Qda. El Cojo & 2,42 & 1,62 & 62,63 & 47,75 & 0,55 & 276 & 50 \\
Qda. Camurí Chiquito & 2,34 & 1,34 & 40,15 & 30,67 & 0,57 & 288 & 50 \\
Qda. San Julián & 2,39 & 1,66 & 22,00 & 16,92 & 0,55 & 350 & 100 \\
Qda. Seca & 2,84 & 1,29 & 58,82 & 46,37 & 0,57 & 134 & 35 \\
Río Cerro Grande & 2,07 & 1,59 & 32,39 & 24,82 & 0,55 & 630 & 125 \\
Río Uria & 2,18 & 1,32 & 44,08 & 34,57 & 0,50 & 400 & 35 \\
Río Naiguatá & 2,15 & 1,50 & 29,57 & 22,47 & 0,57 & 705 & 125 \\
Río Camurí Grande & 1,92 & 1,16 & 36,98 & 29,11 & 0,53 & 662 & 75 \\
Valor máximo = & 2,84 & 1,66 & 76,92 & 60,85 & 0,58 & 886 & 125 \\
Valor mínimo = & 1,92 & 1,16 & 15,48 & 11,72 & 0,50 & 127 & 35 \\
Media = & 2,26 & 1,41 & 40,83 & 31,51 & 0,55 & 384,54 & 63 \\
Moda = & - & - & - & - & - & - & 50 \\
Mediana = & 2,18 & 1,35 & 40,15 & 30,57 & 0,55 & 288 & 50 \\
Varianza = & 0,05 & 0,02 & 288,07 & 181,42 & 0,001 & 64435,60 & 1077,24 \\
Desviación estándar = & 0,23 & 0,15 & 16,97 & 13,47 & 0,02 & 253,84 & 32,82 \\
Asimetría = & 1,15 & 0,27 & 0,74 & 0,81 & $-0,85$ & 0,79 & 1,22 \\
Curtosis = & 2,12 & $-0,85$ & 0,40 & 0,57 & $-0,28$ & $-0,66$ & 0,06 \\
Coeficiente de variación $=$ & 0,10 & 0,11 & 0,42 & 0,43 & 0,04 & 0,66 & 0,52 \\
Primer cuartil = & 2,14 & 1,32 & 29,57 & 22,47 & 0,55 & 164 & 40,00
\end{tabular}


Geomorfometría de Cuencas de Drenaje de La Vertiente Norte del Macizo “El Ávila” (Estado Vargas, Venezuela)

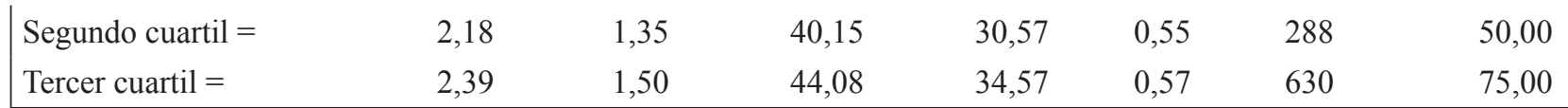

$R_{\mathrm{Lm}}=$ relación de longitud media; $R_{p m}=$ relación de pendiente media; $F_{m c}=$ frecuencia media de las corrientes totales de la red de drenaje; $C t=$ coeficiente de torrencialidad; $C a=$ coeficiente de almacenamiento; $M=$ magnitud de la cuenca; $a_{\text {máx }}=$ ancho máximo de la sección hidráulica de interés.

Las pendientes medias del relieve se corresponden con valores moderados a altos, los cuales abarcan entre $24 \%$ y $34 \%$ con un promedio de $30 \%$ (Figura 4), por encima del cual destacan los promedios de las cuencas de las quebradas Osorio, Cariaco, El Cojo y San Julián y de los ríos Cerro Grande y Naiguatá. Para el caso de las concavidades de los perfiles longitudinales de las quebradas Curucutí, Cariaco, El Cojo y San Julián, y de los ríos Naiguatá y Camurí Grande, sus valores oscilan entre 0,47 y 0,71 , siendo estos los más altos del sector. Otro grupo de cuencas presenta por el contrario, valores menos pronunciados ubicados entre 0 y 0,39 (Tabla 2), con perfiles de morfologías más bien tendentes hacia la convexidad. Los valores de las pendientes promedios de los perfiles longitudinales de las corrientes principales están comprendidos en un rango entre $20 \%$ y $41 \%$ con un promedio de $27 \%$ (Tabla 3); los valores más altos los exhiben los cursos de agua cuyas cuencas son las de menos superficies, como las de las quebradas Osorio, Cariaco y Seca y la del río Uria. En las cuencas más grandes, por tener los cursos de agua principales mayores recorridos, sus perfiles longitudinales han sido más atenuados y/o suavizados por la erosión regresiva, presentando como consecuencia menores valores de pendientes promedios (Figura 5).

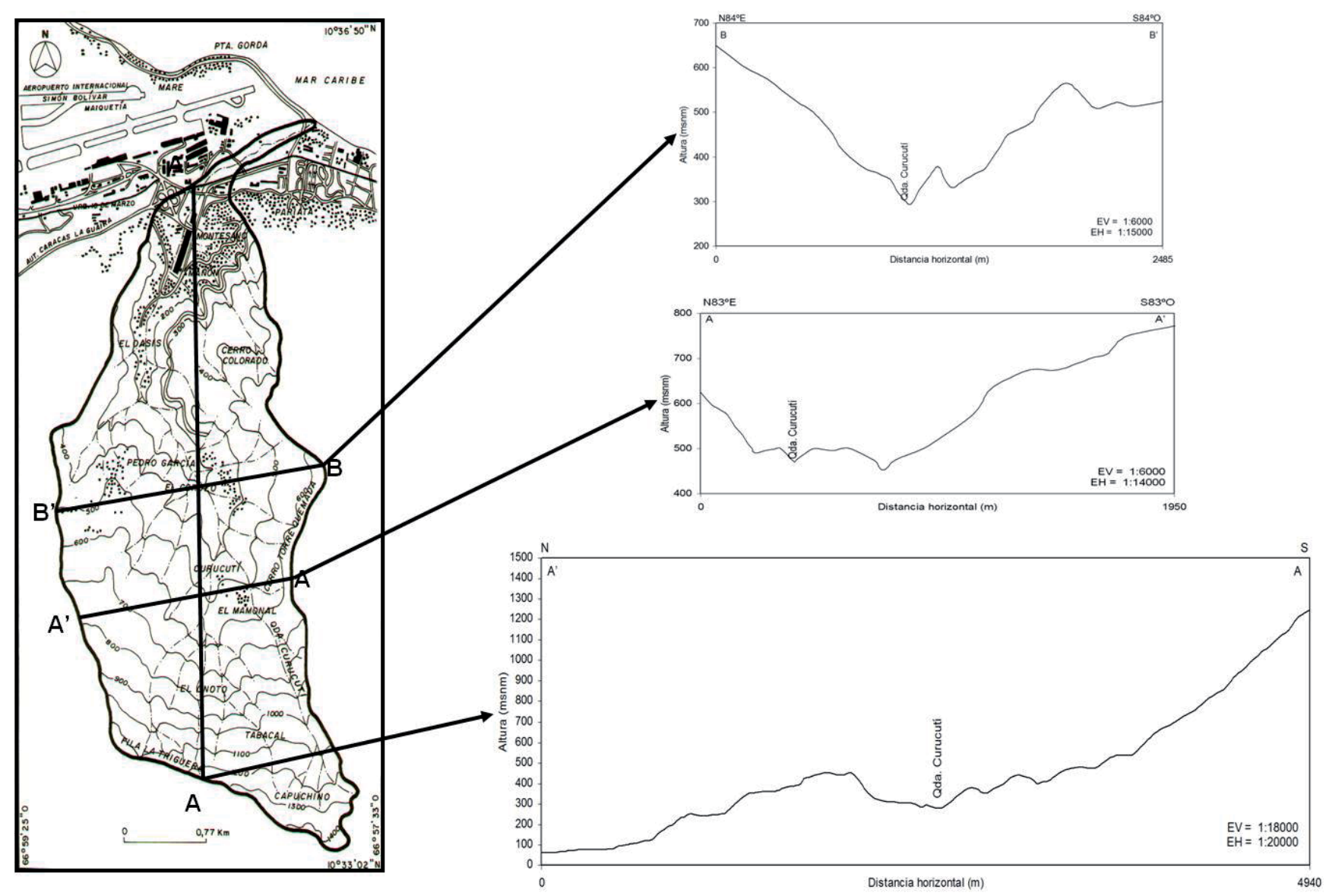

Figura 4 - Ejemplos de perfiles topográficos transversales y longitudinal de la vertiente norte del macizo "El Ávila” (transeptos realizados en la cuenca de drenaje de la quebrada Curucutí), estado Vargas, Venezuela. 
Tabla 3: Aspectos topográficos y toponímicos de las quebradas y ríos principales de cuencas de drenaje de la vertiente norte del macizo “El Ávila”, estado Vargas, Venezuela.

\begin{tabular}{|c|c|c|c|c|c|c|c|c|c|c|}
\hline $\begin{array}{c}\text { Río o } \\
\text { quebrada }\end{array}$ & $\begin{array}{l}\text { Altitud de } \\
\text { la naciente } \\
\left(\mathrm{H}_{\mathrm{n}}\right) \\
(\mathrm{msnm})\end{array}$ & \multicolumn{2}{|c|}{$\begin{array}{l}\text { Descripción } \\
\text { toponímica }\end{array}$} & \multicolumn{2}{|c|}{$\begin{array}{l}\text { Altitud del } \\
\text { desagüe }^{\mathrm{a}} \\
\left(\mathrm{h}_{\mathrm{d}}\right) \\
(\mathrm{msnm})\end{array}$} & $\begin{array}{l}\text { Descripción } \\
\text { toponímica }\end{array}$ & $\begin{array}{l}\text { Altitud } \\
\text { de la } \\
\text { desemb. } \\
(\mathrm{msnm})\end{array}$ & \multicolumn{2}{|c|}{$\begin{array}{l}\text { Descripción } \\
\text { toponímica }\end{array}$} & $\begin{array}{c}\text { Altitud } \\
\text { de origen } \\
\text { del cauce } \\
\text { de orden } \\
\text { mayor } \\
(\mathrm{msnm})\end{array}$ \\
\hline Qda. Curucutí & 1400 & \multicolumn{2}{|c|}{$\begin{array}{l}\text { Vertiente norte de } \\
\text { la fila La Triguera, } \\
\text { al sur de los } \\
\text { caseríos Tabacal y } \\
\text { Capuchino }\end{array}$} & \multicolumn{2}{|l|}{125} & \multicolumn{2}{|l|}{ Barrio La Pedrera } & \multicolumn{2}{|c|}{$\begin{array}{l}\text { Al este de Punta } \\
\text { Gorda y del } \\
\text { Aeropuerto } \\
\text { Internacional } \\
\text { de Maiquetía } \\
\text { Simón Bolívar, y } \\
\text { norte del barrio } \\
\text { Atanasio Girardot. } \\
\text { Localidad Pariata }\end{array}$} & 350 \\
\hline $\begin{array}{l}\text { Qda. Piedra } \\
\text { Azul }\end{array}$ & 1900 & $\begin{array}{l}\text { Vertier } \\
\text { topo Ir }\end{array}$ & $\begin{array}{l}\text { e norte del } \\
\text { iernito }\end{array}$ & 60 & & $\begin{array}{l}\text { Barrios El Rincón y } \\
\text { Quenepe }\end{array}$ & 0 & \multicolumn{2}{|c|}{$\begin{array}{l}\text { Al oeste del } \\
\text { Puerto de La } \\
\text { Guaira. Localidad } \\
\text { Maiquetía }\end{array}$} & 500 \\
\hline Qda. Osorio & 1770 & \multicolumn{2}{|c|}{$\begin{array}{l}\text { Al noroeste del } \\
\text { picacho de Galipán } \\
\text { y del caserío El } \\
\text { Palmar de Cariaco }\end{array}$} & \multicolumn{2}{|l|}{25} & \multicolumn{2}{|l|}{$\begin{array}{l}\text { Casco colonial de La } \\
\text { Guaira }\end{array}$} & \multicolumn{2}{|c|}{$\begin{array}{l}\text { Al este del Puerto } \\
\text { de La Guaira. } \\
\text { Localidad La } \\
\text { Guaira }\end{array}$} & 870 \\
\hline Qda. Cariaco & 1925 & \multicolumn{2}{|c|}{$\begin{array}{l}\text { Vertiente norte del } \\
\text { picacho de Galipán }\end{array}$} & \multicolumn{2}{|l|}{25} & $\begin{array}{l}\text { Barrio de Punta de } \\
\text { Mulatos }\end{array}$ & 0 & \multicolumn{2}{|c|}{$\begin{array}{l}\text { Sector oeste de la } \\
\text { Punta Mulatos. } \\
\text { Localidad Punta } \\
\text { Mulatos }\end{array}$} & 430 \\
\hline $\begin{array}{l}\text { Río San José } \\
\text { de Galipán }\end{array}$ & 2220 & \multicolumn{2}{|c|}{$\begin{array}{l}\text { Al noreste del pico } \\
\text { El Ávila }\end{array}$} & \multicolumn{2}{|l|}{25} & $\begin{array}{l}\text { Localidad de } \\
\text { Macuto, Urb. Trigas } \\
\text { (La Veguita) }\end{array}$ & 0 & \multicolumn{2}{|c|}{ Localidad Macuto } & 1420 \\
\hline Qda. El Cojo & 1890 & & - & \multicolumn{2}{|l|}{50} & $\begin{array}{l}\text { Antigua estación del } \\
\text { Teleférico }\end{array}$ & 0 & \multicolumn{2}{|c|}{$\begin{array}{l}\text { Sector oeste de } \\
\text { la Punta El Cojo. } \\
\text { Localidad El Cojo }\end{array}$} & 304 \\
\hline $\begin{array}{l}\text { Qda. Camurí } \\
\text { Chiquito }\end{array}$ & 2300 & \multicolumn{2}{|c|}{$\begin{array}{l}\text { Al noroeste del pico } \\
\text { Occidental }\end{array}$} & \multicolumn{2}{|l|}{50} & Sector La Llanada & 0 & \multicolumn{2}{|c|}{$\begin{array}{l}\text { Balneario Camurí } \\
\text { Chico }\end{array}$} & 1185 \\
\hline $\begin{array}{l}\text { Qda. San } \\
\text { Julián }\end{array}$ & 2305 & \multicolumn{2}{|c|}{$\begin{array}{l}\text { Vertiente norte de } \\
\text { la silla de Caracas, } \\
\text { entre el pico } \\
\text { Occidental y el pico } \\
\text { Oriental }\end{array}$} & \multicolumn{2}{|l|}{105} & Urb. Viposa & 0 & \multicolumn{2}{|c|}{$\begin{array}{l}\text { Punta Caribe. } \\
\text { Entre las } \\
\text { localidades } \\
\text { Camurí al oeste y } \\
\text { El Caribe al este }\end{array}$} & 500 \\
\hline Qda. Seca & 1200 & $\begin{array}{l}\mathrm{Al} \text { este } \\
\text { hacien }\end{array}$ & $\begin{array}{l}\text { de la } \\
\text { a El Rosario }\end{array}$ & 50 & & $\begin{array}{l}\text { Barrio Quebrada } \\
\text { Seca }\end{array}$ & 0 & \multicolumn{2}{|c|}{$\begin{array}{l}\text { Al este de la Punta } \\
\text { Caraballeda. Entre } \\
\text { las localidades } \\
\text { Caraballeda } \\
\text { al oeste y } \\
\text { Tanaguarena al } \\
\text { este }\end{array}$} & 750 \\
\hline $\begin{array}{l}\text { Río Cerro } \\
\text { Grande }\end{array}$ & 2550 & \multicolumn{2}{|c|}{$\begin{array}{l}\text { Al noreste del } \\
\text { estribo de Galindo }\end{array}$} & \multicolumn{2}{|l|}{25} & Urb. Tanaguarena & 0 & \multicolumn{2}{|c|}{$\begin{array}{l}\text { Al este de la Punta } \\
\text { Cerro Grande. } \\
\text { En la localidad } \\
\text { Tanaguarena }\end{array}$} & 100 \\
\hline Río Uria & 2275 & \multicolumn{2}{|r|}{-} & \multicolumn{2}{|l|}{40} & Hacienda Uria & 0 & $\begin{array}{l}\text { Boca d } \\
\text { Localic }\end{array}$ & $\begin{array}{l}\text { ria. } \\
\text { Jria }\end{array}$ & 575 \\
\hline Río Naiguatá & 2525 & $\begin{array}{l}\text { Al nor } \\
\text { estribo }\end{array}$ & $\begin{array}{l}\text { ste del } \\
\text { de Galindo }\end{array}$ & 25 & & $\begin{array}{l}\text { Hacienda Longa } \\
\text { España }\end{array}$ & 0 & $\begin{array}{l}\text { Al oest } \\
\text { localid }\end{array}$ & $\begin{array}{l}\text { la } \\
\text { aiguatá }\end{array}$ & 375 \\
\hline $\begin{array}{l}\text { Río Camurí } \\
\text { Grande }\end{array}$ & 2265 & $\begin{array}{l}\mathrm{Al} \text { este } \\
\text { Tacam }\end{array}$ & $\begin{array}{l}\text { del topo } \\
\text { haco }\end{array}$ & 30 & & $\begin{array}{l}\text { Núcleo de la USB, } \\
\text { Urb. Camurí Grande }\end{array}$ & 0 & $\begin{array}{l}\text { Punta } \\
\text { Grande } \\
\text { Camuri }\end{array}$ & $\begin{array}{l}\text { urí } \\
\text { calidad } \\
\text { ande }\end{array}$ & 230 \\
\hline $\begin{array}{c}\text { Río o } \\
\text { quebrada }\end{array}$ & $\begin{array}{r}\text { Pendiente na } \\
\text { - desemboc } \\
(\%)\end{array}$ & $\begin{array}{l}\text { ciente } \\
\text { Idura }\end{array}$ & $\begin{array}{r}\text { Pendiente } \\
- \text { des } \\
(\%\end{array}$ & ciente & & $\begin{array}{l}\text { iente desagüe } \\
\text { sembocadura } \\
(\%)\end{array}$ & $\begin{array}{r}\text { Pendiente o } \\
\text { orden may } \\
\text { desembocadu }\end{array}$ & $\begin{array}{l}\text { gen } \\
- \\
(\%) \\
\end{array}$ & $\begin{array}{r}\text { Pendi } \\
\text { orde } \\
\text { des } \\
\end{array}$ & $\begin{array}{l}\text { ente origen } \\
\text { mayor - } \\
\text { güe }(\%)\end{array}$ \\
\hline Qda. Curucutí & 18,12 & & 27 , & & & 5,15 & 7,22 & & & 9,58 \\
\hline Qda. Piedra & 21,16 & & 21 , & & & 4,80 & 11,57 & & & 4,40 \\
\hline
\end{tabular}


Geomorfometría de Cuencas de Drenaje de La Vertiente Norte del Macizo “El Ávila” (Estado Vargas, Venezuela)

\begin{tabular}{llllcc|} 
Qda. Osorio & 32,95 & 36,06 & 6,20 & 23,80 & 27,94 \\
Qda. Cariaco & 35,92 & 41,15 & 6,45 & 14,01 & 15,71 \\
$\begin{array}{l}\text { Río San José } \\
\text { de Galipán }\end{array}$ & 21,70 & 21,06 & 4,74 & 21,38 & 21,52 \\
$\begin{array}{l}\text { Qda. El Cojo } \\
\text { Qda. Camurí }\end{array}$ & 22,48 & 25,30 & 5,81 & 8,47 & 9,51 \\
$\begin{array}{l}\text { Chiquito } \\
\begin{array}{l}\text { Qda. San } \\
\text { Julián }\end{array}\end{array}$ & 25,78 & 27,70 & 5,69 & 19,67 & 21,10 \\
$\begin{array}{l}\text { Qda. Seca } \\
\text { Río Cerro }\end{array}$ & 19,96 & 21,74 & 5,38 & 8,40 & 9,48 \\
$\begin{array}{l}\text { Grande } \\
\text { Río Uria }\end{array}$ & 27,23 & 33,73 & 5,72 & 20,82 & 29,61 \\
Río Naiguatá & 20,81 & 21,20 & 2,94 & 4,04 & 4,82 \\
Río Camurí & 35,29 & 37,43 & 4,76 & 14,75 & 18,44 \\
Grande & 19,26 & 20,50 & 2,44 & 4,91 & 5,31 \\
\hline
\end{tabular}

${ }^{a}$ Se corresponde con el frente de montaña y/o del ápice del abanico aluvial.

${ }^{b}$ Desembocadura

Nota. Tabla elaborada con información tomada de planos topográficos del "Proyecto BITUCOTEX” a escala 1:5.000 por DCN, 1958, Caracas; y de las Hojas “Maiquetía” (6847-IV-NO), “El Caribe” (6847-IV-NE), y ”Naiguatá” (6847-I-NO a escala 1:25.000 por DCN, 1979, Caracas; planos topográficos a escala 1:5.000 por Gobernación del Distrito Federal, 1984, Caracas; y ortofotomapas a escala 1:25.000 por SAGECAN, 1995, Caracas.

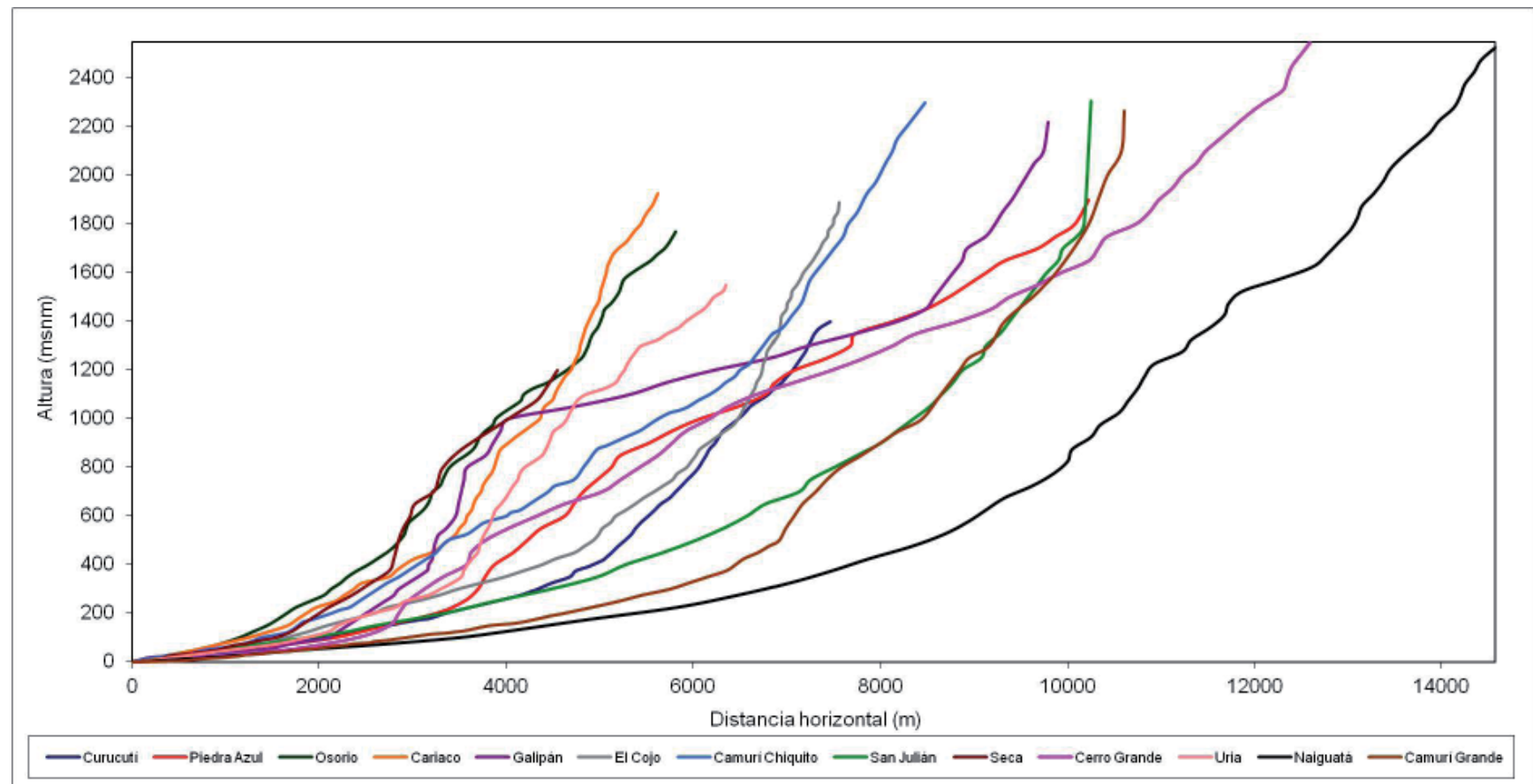

Figura 5 - Perfiles topográficos longitudinales de los cauces principales de ríos y quebradas de la vertiente norte del macizo “El Ávila”, estado Vargas, Venezuela. Perfiles elaborados a partir de planos topográficos a escala 1:5.000 por DCN, 1958, Caracas; y planos topográficos del “Proyecto BITUCOTEX” a escala 1:5.000 por Gobernación del Distrito Federal, 1984, Caracas. 
Los valores de relieve máximo de las corrientes principales oscilan entre $1.150 \mathrm{~m}$ y $2.525 \mathrm{~m}$ con un promedio de 1.991,54 m (Tabla 2). El factor topográfico de las corrientes principales nos expresa una idea de variabilidad promedio de los gradientes topográficos experimentados por los cauces de éstas a lo largo de sus recorridos, y cuyos valores fluctúan entre 666,30 y 1.367,37 con un promedio de 1.020,23. Otro rasgo cuantitativo importante del relieve y con gran repercusión en el comportamiento torrencial de las cuencas, lo constituyen las pendientes medias de los totales de corrientes de las redes de drenaje, con valores que superan al $50 \%$ en todos los casos y un promedio de $65 \%$. En general todas las cuencas de drenaje del área de estudio muestran valores bajos (curvas hipsométricas morfológicamente tendentes hacia la concavidad $<0,50$ ) en cuanto a sus integrales hipsométricas, lo cual es concordante con sus valores de concavidad (Tabla 2). La única cuenca de drenaje que presenta un valor superior a 0,50 corresponde a la quebrada San José de Galipán, cuya curva dibuja un perfil tendente a lo convexo, carácter definido por el control tectónico - estructural sobre el mismo.

Los coeficientes de masividad expresan en líneas generales valores altos para todas las cuencas de drenaje, los cuales corroboran el desarrollo de sistemas hidrogeomorfológicos en ambientes montañosos. Estos coeficientes de masividad abarcan un rango entre $34,74 \mathrm{msnm} / \mathrm{km}^{2}$ y $195,57 \mathrm{msnm} / \mathrm{km}^{2}$ (moderadamente montañosas a muy montañosas) con un promedio de $98,66 \mathrm{msnm} / \mathrm{km}^{2}$ (Tabla 2). Estas consideraciones también se aprecian de manera muy similar en los datos de los coeficientes orográficos, los cuales están entre $36.620,01$ y $154.518,28$ con un promedio de $84.764,85$. Con relación al relieve relativo se observa, que dichos valores son más altos en las cuencas de menores superficies, debido a que la proporción de desnivel o relieve máximo por unidad de longitud del perímetro es mayor. El relieve relativo comprende valores entre $92,20 \mathrm{~m} / \mathrm{km}$ y $180,88 \mathrm{~m} / \mathrm{km}$ con un promedio de 136,94 m/km (Tabla 2). De igual manera, los números de rugosidad de Melton son mayores en las cuencas más pequeñas, como consecuencia de mayores proporciones de desniveles altitudinales máximos por unidad de área; dichos valores comprenden un rango de 0,42 hasta 0,91 con un promedio de 0,63 (Tabla 2).

\section{Forma de la Cuenca}

La expresión morfológica del trazado de los perímetros de las cuencas sobre la base cartográfica, evidencian la predominancia de formas alargadas con orientaciones prevalentemente norte - sur (entre $\mathrm{N} \mathrm{a}$ $\mathrm{N} 35^{\circ} \mathrm{O}$ y $\mathrm{N} 04^{\circ} \mathrm{E}$ a N $32^{\circ} \mathrm{E}$ ) y perpendiculares a cuasi-perpendiculares a la línea de costa (Figura 3). Los valores de elongación calculados indican en líneas generales que todas las cuencas presentan formas elongadas o alargadas con una configuración algo rectangular; los valores de este parámetro oscilan entre 0,48 y 0,68 con un promedio de 0,57 (Tabla 2). Las cuencas más elongadas corresponden a las de las quebradas Osorio, Cariaco y Camurí Chiquito cuyos valores son $\leq 0,50$, mientras que en el resto dicho atributo es más moderado, y para el caso de la cuenca de la quebrada Piedra Azul, esta se presenta como una cuenca ligeramente elongada.

Los valores de los perímetros relativos de crenulación nos dan una idea de la complejidad o irregularidad de la forma planimétrica de las cuencas, definidas por los contornos dibujados por sus correspondientes perímetros por unidad de área; sus valores comprenden un rango entre 16,00 y 25,94 con un promedio de 21,38 (Tabla 2), entre las que destacan como las formas más irregulares las correspondientes a las cuencas de las quebradas Cariaco, Camurí Chiquito y Osorio. El coeficiente de compasidad muestra valores que definen a la mayoría de las formas de las cuencas como oval-redonda a oval-oblonga (entre 1,25 y 1,43), mientras que de manera particular, las cuencas de las quebradas San Julián y Seca presentan formas más bien casi redonda a oval redonda $(1,21$ y 1,12 respectivamente). Según los valores obtenidos para los índices de alargamiento, las cuencas de drenaje de los ríos Uria y Naiguatá clasifican como poco alargadas y las cuencas de las quebradas El Cojo y Camurí Chiquito como muy alargadas; el resto de las cuencas caen dentro de la categoría moderadamente alargadas. Los valores de este parámetro de forma se ubican en un rango comprendido entre 1,36 y 3,01 con un promedio de 2,03 (Tabla 2).

En cuanto a los índices de homogeneidad, las cuencas de drenaje que presentan estrechas diferencias entre sus áreas naturales y las áreas de sus respecti- 
vos rectángulos equivalentes, son las que muestran precisamente mayor homogeneidad, mientras que las de mayores diferencias entre las áreas mencionadas son menos homogéneas. Los valores para este índice oscilan entre 0,51 y 0,77 con un promedio de 0,64 (Tabla 2). De acuerdo con los resultados, las cuencas de drenaje de las quebradas Curucutí, Piedra Azul y San José de Galipán y de los ríos Naiguatá y Camurí Grande son las más asimétricas, mientras que el resto de las cuencas tienden más hacia la simetría de sus sistemas. Los valores de simetría están comprendidos entre 1,01 y 4,38 con un promedio de 1,89 (Tabla 2). Los datos del factor forma corroboran lo afirmado para el índice de alargamiento y la elongación, sus valores se ubican entre 0,23 y 0,46 con un promedio de 0,33 ; según este parámetro las cuencas de drenaje más alargadas son las correspondientes a los menores valores del mismo, como es el caso de Osorio, Cariaco, El Cojo y Camurí Chiquito con factores de forma entre 0,23 y 0,26 (Tabla 2 ).

Las cuencas de drenaje más alargadas son las correspondientes a los mayores valores del alargamiento de Caquot, lo cual es coincidente para las cuencas de las quebradas Osorio, Cariaco, El Cojo y Camurí Chiquito. Este parámetro presenta datos que abarcan un rango entre 1,48 y 2,08 con un promedio de 1,77 (Tabla 2). Nuevamente los valores correspondientes a los radios de elongación, nos reafirman lo discutido y expuesto para los parámetros índice de alargamiento, elongación y factor forma. Este radio muestra valores entre 0,54 y 0,76 con un promedio de 0,64 . La estimación de los radios de circularidad arrojaron valores entre 0,48 y 0,79 con un promedio de 0,60 (Tabla 2 ), indicando para el caso de las cuencas de drenaje de las quebradas Curucutí, Piedra Azul, San Julián y Seca y de los ríos Naiguatá y Camurí Grande, una tendencia hacia la circularidad a diferencia del resto de las cuencas. Según los índices de forma, cuyos valores oscilan entre 1,60 y 2,03 con un promedio de 1,84 (Tabla 2), las cuencas más alargadas corresponden a las de las quebradas Osorio, Cariaco y Camurí Chiquito, y a las de los ríos San José de Galipán y Uria.

El parámetro referido a la relación entre el largo y el área de las cuencas muestra un solo valor $(1,13)$ para las trece cuencas de drenaje consideradas en este estudio, por lo que no aporta ninguna información valiosa que permita discriminar entre estos sistemas según su forma. Por su parte, los índices de forma presentan valores entre 1,60 y 2,03 con promedio de 1,84 (Tabla 2), lo cuales indican que las cuencas de drenaje de las quebradas Cariaco, Camurí Chiquito y Osorio y de los ríos San José de Galipán y Uria son las de morfología más alargadas, mientras que las correspondientes a la quebrada San Julián y a los ríos Cerro Grande y Naiguatá, tienden hacia morfologías más bien semi-circulares; el resto de las cuencas se mantienen en formas intermedias. Los coeficientes de forma exhiben valores entre 0,23 y 0,46 con un promedio de 0,33 (Tabla 2), con los cuales las cuencas de las quebradas Curucutí, Osorio, Cariaco, El Cojo, Camurí Chiquito y Seca y de los ríos Cerro Grande y Camurí Grande se categorizan como ligeramente achatadas; y las cuencas de las quebradas Piedra Azul, San Julián y de los ríos Uria y Naiguatá califican como moderadamente achatadas, condiciones éstas que favorecen la tendencia de estos sistemas a generar crecidas importantes. Finalmente, los coeficientes de redondez exhiben valores que se encuentran entre 1,72 y 3,40 con un promedio de 2,50 (Tabla 2), y con base en los cuales califican como más redondeadas las cuencas de drenaje de la quebrada Piedra Azul y la del río Naiguatá.

\section{Extensión de la Red de Drenaje}

Los cursos de agua principales de las cuencas de drenaje son todos en general de cortos recorridos $(\leq 10 \mathrm{~km})$ a excepción de los ríos Cerro Grande y Naiguatá, cuyas longitudes son de $11,75 \mathrm{~km}$ y 13,55 $\mathrm{km}$ respectivamente. Análogamente, las longitudes medias de los valles de estas corrientes principales también son cortas, con recorridos entre $3 \mathrm{~km}$ y 11 $\mathrm{km}$ y promedio de $6,75 \mathrm{~km}$ (Tabla 2). Las longitudes totales de las corrientes de las redes de drenaje son de magnitudes importantes para tratarse de sistemas categorizados como microcuencas (Figura 6). Sus valores se encuentran entre $34,03 \mathrm{~km}$ y $255,55 \mathrm{~km}$ con un promedio de 123,33 km (Tabla 2). En conjunto, los valores obtenidos de sinuosidad total, sinuosidad topográfica y sinuosidad hidráulica para las corrientes principales, afirman que se trata de cursos de agua con trayectorias rectilíneas y/o de muy baja sinuosidad. El aspecto rectilíneo de estos cursos de agua aunado a sus cortos recorridos definen centros de gravedad de valores muy bajos, los cuales oscilan entre 1,78 y 6,78 con promedio de 3,93 (Tabla 2). 


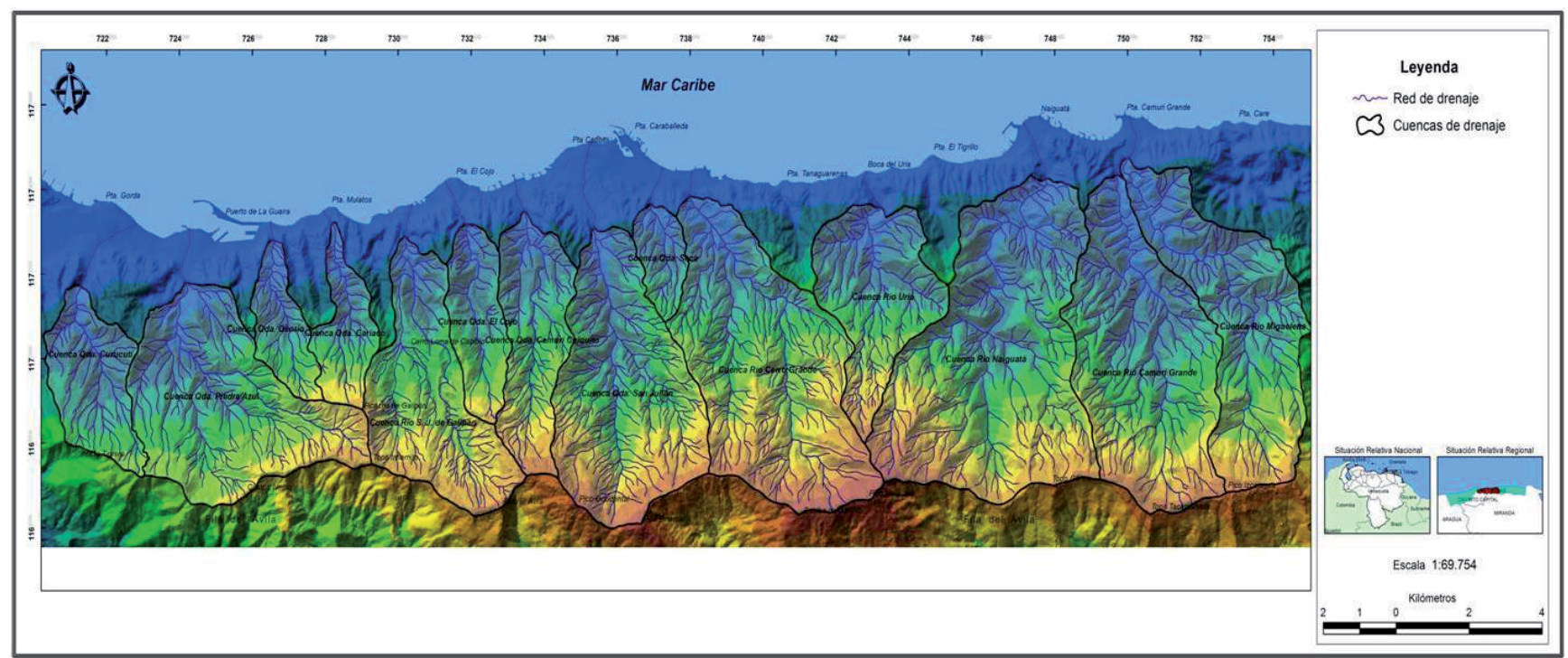

Figura 6 - Redes de drenaje de cuencas de la vertiente norte del macizo “El Ávila”, estado Vargas, Venezuela. Figura y MEDT elaborados con base cartográfica tomada de las Hojas “Maiquetía” (6847-IV-NO), “El Caribe” (6847-IV-NE), ”Naiguatá” (6847-I-NO), “23 de Enero” (6847-IV-SO), “Los Chorros” (6847-IV-SE) y “Curupao” (6847-I-SO) a escala 1:25.000 por Dirección de Cartografía Nacional [DCN], 1979, Caracas.

El parámetro más importante en la definición de la extensión de un sistema de drenaje natural es su densidad de drenaje. Para el caso de las cuencas del área de estudio estos valores califican como medios a altos, con magnitudes que fluctúan entre $5,63 \mathrm{~km} / \mathrm{km}^{2} \mathrm{y}$ $14,77 \mathrm{~km} / \mathrm{km}^{2}$, definiendo a su vez texturas de drenaje medias (Tabla 2). Estas observaciones son complementadas con los datos obtenidos para los parámetros textura del drenaje, textura topográfica e intensidad del drenaje. Las redes de drenaje están constituidas por cauces o corrientes de agua de cortos recorridos y regímenes intermitentes que en conjunto muestran patrones de tipo subdendríticos a subparalelos, los cuales son definidos principalmente por las pendientes de las corrientes de órdenes 2 y 3 que producen un cierto grado de paralelismo, la existencia de sistemas de fracturas (diaclasas y fallas), y los desniveles topográficos entre bloque tectónicos, que también ejercen control en la disposición y distribución de las corrientes que conforman dichas redes.

Los coeficientes de mantenimiento del canal muestran valores muy bajos que comprenden un rango entre $0,07 \mathrm{~km}^{2} / \mathrm{km}$ y $0,18 \mathrm{~km}^{2} / \mathrm{km}$ con un promedio de $0,11 \mathrm{~km}^{2} / \mathrm{km}$ (Tabla 2), lo que significa que por cada kilómetro de cauce existen áreas de drenaje muy pequeñas, indicando el corto recorrido de la escor- rentía laminar para fluir hasta el cauce más cercano, así como la prevalencia de la escorrentía concentrada sobre esta última. Esta característica del drenaje y de la escorrentía en las cuencas se reafirma con los valores obtenidos para los parámetros extensión media de la escorrentía superficial, longitud del flujo superficial y alejamiento medio (Tabla 2).

\section{Orden y Magnitud de la Red de Drenaje}

Del análisis, ordenamiento y jerarquización de las corrientes de agua que conforman las redes de drenaje, se obtuvo que las mismas corresponden a sistemas hidrogeomorfológicos de órdenes 4 (cuencas de las quebradas Osorio y Seca), 5 (cuencas de las quebradas Curucutí, Piedra Azul, Cariaco, El Cojo, Camurí Chiquito y San Julián y del río Uria) y 6 (cuencas de los ríos San José de Galipán, Cerro Grande, Naiguatá y Camurí Grande) (Tabla 2). La amplitud y ramificación de las redes se puede apreciar principalmente a partir del número total de cauces correspondientes a los órdenes 1 y 2 , cuyos valores oscilan entre 127 y 886 con promedio de 384,5 y entre 28 y 178 con promedio de 87 respectivamente (Tabla 2), considerando que en estos órdenes prevalecen procesos erosivos que contribuyen a la expansión y crecimiento de los 
sistemas. El número total de corrientes de órdenes sucesivos decrece desde las corrientes de orden 1 hacia la corriente de orden mayor, siguiendo una progresión geométrica que tiende a ser constante. Vistas las redes de drenaje bajo la totalidad del número de cauces de todos los órdenes que las estructuran, presentan un rango entre 169 y 1120 con promedio de 497,54 (Tabla 2). Al respecto, es oportuno indicar que entre el $75 \%$ y el $80 \%$ de las corrientes que conforman a las redes de drenaje, son de orden 1.

En cuanto a las relaciones de bifurcación entre los distintos órdenes sucesivos de los cauces, la mayoría de los casos se ubican entre 4 y 5 , indicando uniformidad y efectividad en los sistemas de evacuación de las aguas de escorrentía; cabe destacar que estos datos se corresponden con el rango propuesto por Strahler (1985) como valores característicos de los complejos fluviales, con lo cual se cumple para estas cuencas la denominada Ley del Número de Cauces de Horton.
Esta afirmación se corrobora mejor todavía con los valores obtenidos para las relaciones de bifurcación media de cada cuenca en particular, los cuales oscilan entre 3,58 y 4,99 con un promedio de 4,10 (Tabla 2 y Figuras 7 y 8 ).

Las longitudes totales de las corrientes de órdenes sucesivos decrecen significativamente desde el orden 1 hasta el orden mayor de cada cuenca en particular, prácticamente atendiendo a una relación exponencial. Las longitudes totales de las corrientes de orden 1 presentan valores entre $21 \mathrm{~km}$ y 155,59 $\mathrm{km}$ con un promedio de $77,19 \mathrm{~km}$, mientras que para los de órdenes 2 están entre $5,73 \mathrm{~km}$ y $52,04 \mathrm{~km}$ con promedio de $24,71 \mathrm{~km}$ (Tabla 2). Las longitudes promedios de las corrientes de orden 1 de todas las cuencas presentan un promedio de $0,20 \mathrm{~km}$, y para el caso de las de órdenes 2 el promedio es de $0,28 \mathrm{~km}$, frente a las corrientes de órdenes superiores $(5$ y 6 ) cuyos promedios son de 2,63 km y 4,63 km (Tabla 2).

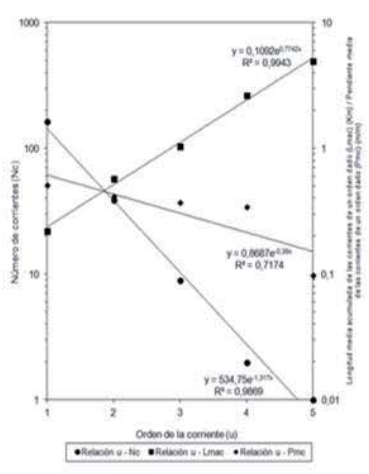

(A)

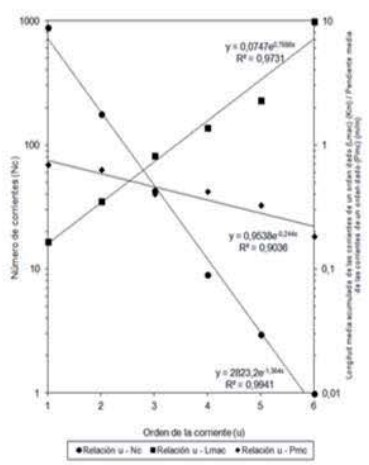

(E)

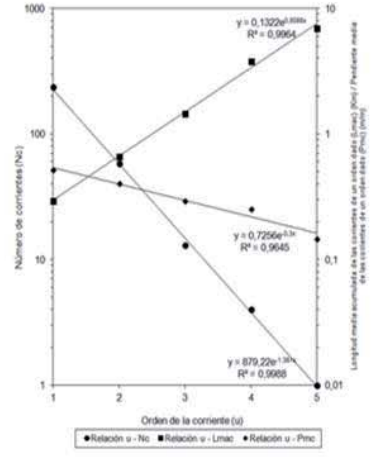

(B)

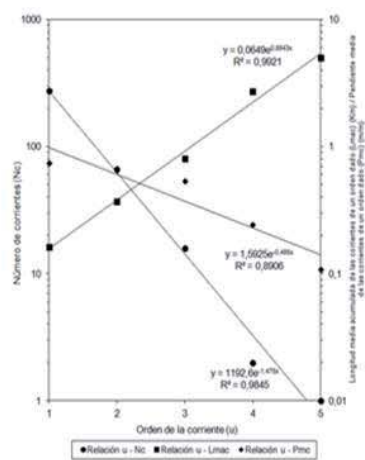

(F)

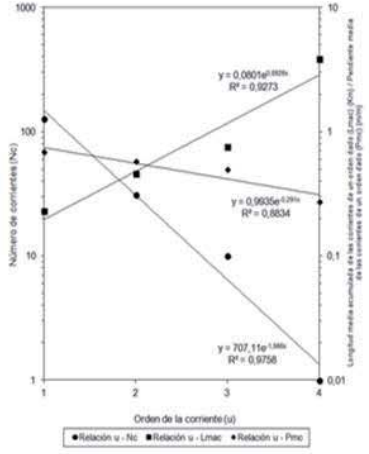

(C)

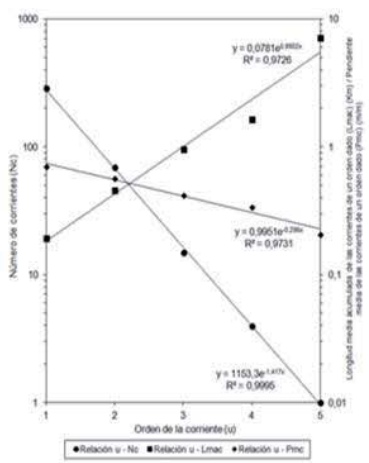

(G)

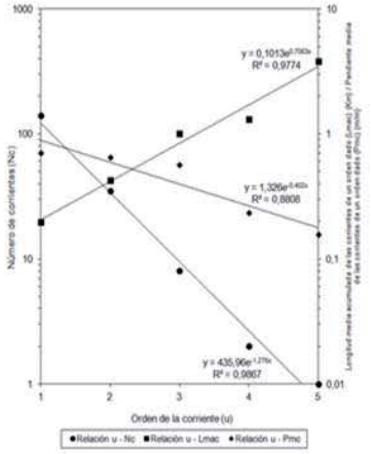

(D)

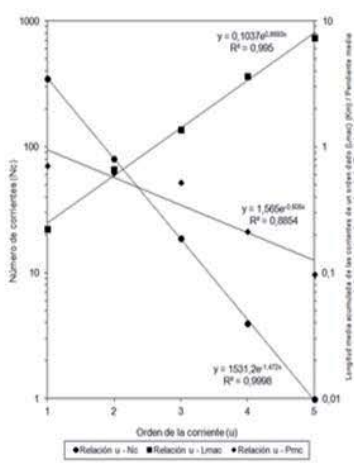

(H)

Figura 7 - Relaciones de bifurcación, longitud y pendiente de redes de drenaje de cuencas de la vertiente norte del macizo "El Ávila” (estado Vargas, Venezuela): (A) quebrada Curucutí, (B) quebrada Piedra Azul, (C) quebrada Osorio, (D) quebrada Cariaco, (E) río San José de Galipán, (F) quebrada El Cojo, (G) quebrada Camurí Chiquito, y (H) quebrada San Julián. 


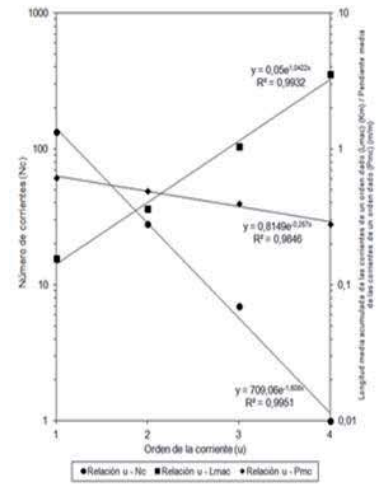

(A)

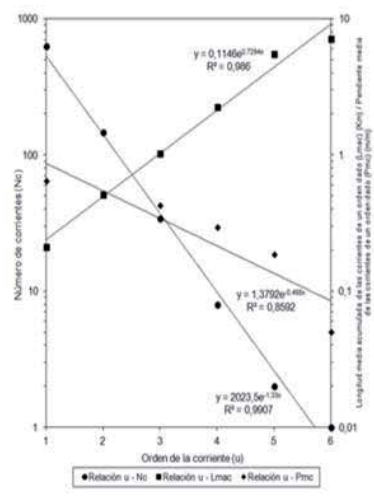

(B)

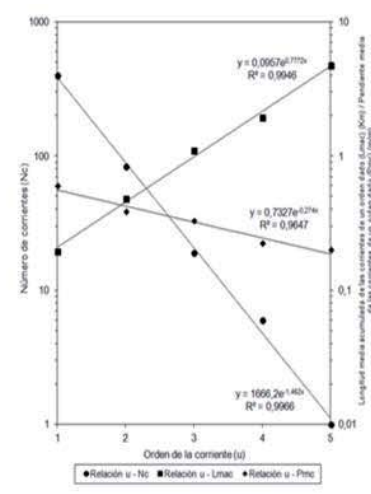

(C)

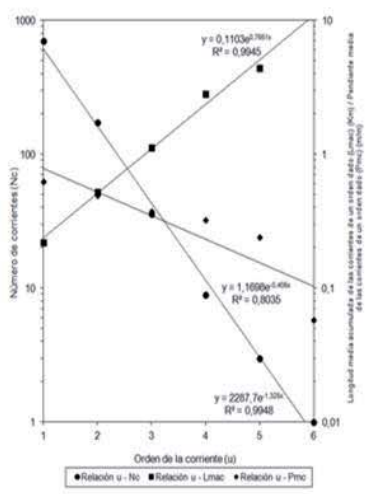

(D)

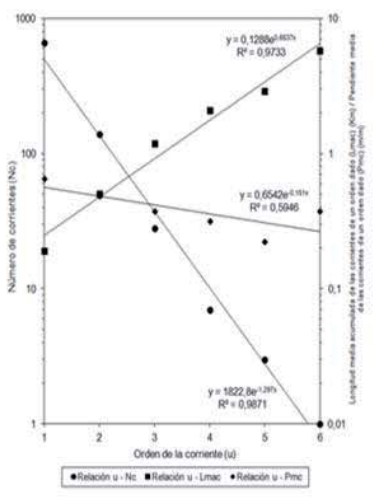

(E)

Figura 8 - Relaciones de bifurcación, longitud y pendiente de redes de drenaje de cuencas de la vertiente norte del macizo "El Ávila" (estado Vargas, Venezuela): (A) Quebrada Seca, (B) río Cerro Grande, (C) río Uria, (D) río Naiguatá, y (E) río Camurí Grande.

Las longitudes medias acumuladas de las corrientes de órdenes sucesivos al igual que el número total de corrientes de órdenes sucesivos, sigue una variabilidad que obedece a una progresión geométrica, pero para el caso de las longitudes medias acumuladas, éstas se incrementan desde las corrientes de orden 1 hacia las corrientes de orden mayor. Las relaciones de longitud de las corrientes de órdenes sucesivos se incrementan de igual manera desde los órdenes menores hacia los órdenes mayores, y por lo general para la mayoría de los casos, sus valores están dentro de los típicos indicados por Strahler (1985).

Ello se corrobora con los datos correspondientes a las relaciones de longitudes medias de cada cuenca en particular, cuyos valores oscilan entre 2 y 3 (Figuras 7 y 8). Sin embargo, en las relaciones de longitud de órdenes sucesivos se observa que en las correspondientes a los órdenes 3/4, 4/5 y 5/6 para algunos casos, los valores no se corresponden con el rango característico para este atributo, con lo cual no se cumple en esos casos la ley de Horton conocida como Ley de la Longitud de los Cauces, debido básicamente a un escaso desarrollo longitudinal de los corrientes de orden menor en cada una de esas relaciones, que se traducen en un valor bajo de longitud media de esos órdenes.

Los desniveles medios de las corrientes de órdenes sucesivos se incrementan significativamente desde las corrientes de orden 1 hacia las corrientes de orden mayor, sin embargo, debido a que se observó lo contrario respecto a las longitudes medias de órdenes sucesivos, las pendientes medias de las corrientes de valores más altos se obtuvieron para los órdenes menores y viceversa, de esta manera los órdenes 1 y 2 de las redes presentan pendientes medias entre 0,65 (65 \%) y 0,53 (53\%), mientras que para los órdenes 5 y 6 se registraron pendientes medias entre $0,18(18 \%)$ y $0,17(17 \%$ ) (Tabla 2). Estas aseveraciones se sustentan de igual manera en los valores de relación de pendiente entre órdenes sucesivos, los cuales decrecen desde las corrientes de órdenes 1 hacia las corrientes de orden mayor. En cuanto a las relaciones de pendiente media para cada una de las cuencas del sector bajo estudio, se 
presentan valores bastante uniformes que oscilan entre 1 y 2 (Figuras 7 y 8 ), siendo los mismos representativos de sistemas hidrogeomorfológicos bien drenados.

Las frecuencias de las corrientes de distintos órdenes comprenden valores altos con un promedio de $31,51 \mathrm{~N}_{\mathrm{u}} / \mathrm{km}^{2}$ para los órdenes 1 , y muy bajos para los órdenes 5 y 6 que presentan promedios de $0,12 \mathrm{~N}_{\mathrm{u}} / \mathrm{km}^{2}$ y $0,05 \mathrm{~N}_{\mathrm{u}} / \mathrm{km}^{2}$ (Tabla 2), los mismos decrecen desde los órdenes 1 hacia los órdenes mayores de las redes. Las frecuencias medias de las corrientes totales de las redes de drenaje presentan valores por lo general altos que comprenden un rango entre $15,48 \mathrm{~N} / \mathrm{km}^{2}$ y $76,92 \mathrm{~N}_{\mathrm{t}} /$ $\mathrm{km}^{2}$ con un promedio de $40,83 \mathrm{~N}_{\mathrm{t}} / \mathrm{km}^{2}$ (Tabla 2). Los coeficientes de torrencialidad muestra también valores altos, contribuyendo de igual manera con lo planteado anteriormente; los valores de este parámetro están entre $11,72 \mathrm{~N}_{1} / \mathrm{km}^{2}$ y $60,85 \mathrm{~N}_{1} / \mathrm{km}^{2}$ con un promedio de 31,51 $\mathrm{N}_{1} / \mathrm{km}^{2}$. Los valores de coeficientes de almacenamiento de las cuencas son de intermedios a bajos y bastante uniformes vistos en la totalidad de los sistemas estudiados, en un rango que abarca desde 0,50 hasta 0,58 con un promedio de 0,55 (Tabla 2 ).

Otro indicador importante del comportamiento torrencial de una cuenca de drenaje y de la intensidad de los procesos erosivos en ella, lo constituye la magnitud de la cuenca representada por el total de corrientes de orden 1 , que para el caso de los sistemas hidrogeomorfológicos de nuestro interés muestran valores comprendidos entre 127 y 886 con un promedio de 384,54 (Tabla 2). Por último, se hace referencia a un parámetro de naturaleza hidráulica como lo es el ancho máximo de la sección hidráulica de interés (ápices de los abanicos), ubicados en los extremos terminales de los cauces de ríos y quebradas principales. En tal sentido, este parámetro mostró valores entre $35 \mathrm{~m}$ y $125 \mathrm{~m}$ con un promedio de $50 \mathrm{~m}$ (Tabla 2).

\section{Discusión}

Las áreas estimadas de cada una de las cuencas de drenaje, las califican bajo la categoría de microcuencas (< $30 \mathrm{~km}^{2}$ ). Estas pequeñas superficies planimétricas por sí solas, permiten hacer algunas consideraciones que tienen implicaciones en sus comportamientos hidrológicos e hidráulicos en presencia de tormentas de precipitación de gran radio y altas intensidades, ya que tales valores de área suponen menores tiempos de concentración de la escorrentía superficial, y mayor susceptibilidad a experimentar crecidas con hidrogramas de picos pronunciados y cortas duraciones. Así mismo, los tiempos de retardo desde el momento en que la precipitación efectiva de una tormenta se transforma en escurrimiento superficial hasta el pico de las crecidas, se hacen más cortos. Estas áreas también denotan que las superficies fuentes de contribución a la escorrentía superficial son pequeñas, y que en presencia de una tormenta de extensión considerable toda el área se activa y aporta agua, lo que favorece la generación de hidrogramas con las características arriba mencionadas. Bajo la no influencia de tormentas, las pequeñas áreas de las cuencas determinan valores de caudales medios bajos, que son alimentados fundamentalmente por los flujos bases y subterráneos.

Las notorias diferencias entre los valores de las áreas mayores y menores de las vertientes de algunas de las cuencas del sector de estudio, permiten interpretarlas como superficies que aportan de manera desigual a la escorrentía que alimenta a los cursos de agua principales. Visto de otra manera, las áreas de las vertientes con mayores superficies planimétricas tienen una gran incidencia sobre las respuestas hidrológicas de sus cuencas, y repercusiones importantes en el comportamiento hidrológico de estos sistemas frente a las precipitaciones, ya que algunos sectores tendrán más aportes a la escorrentía superficial que otros. Otras cuencas muestran valores muy similares entre las áreas generadas por la división de sus quebradas o ríos principales; en estos sistemas la participación de ambas vertientes en la definición de las magnitudes de las respuestas hidrológicas, es más equitativa. Las escasas dimensiones de las cuencas consideradas (más largas que anchas) son también indicadoras de pequeños sistemas con mayor tendencia al crecimiento longitudinal que lateral, lo cual puede interpretarse como una respuesta a la predominancia de la erosión regresiva del curso principal de las quebradas y ríos, sobre el trabajo erosivo de los cursos de agua que drenan perpendicular $u$ oblicuamente hacia éstos a lo largo de sus canales, condicionada por una litología que ofrece poca resistencia a los procesos erosivos, el control de los sistemas de fracturas y la pendiente topográfica regional de la vertiente norte del macizo "El Ávila".

Las diferencias entre altitudes extremas definen relieves máximos que sugieren desniveles y pendientes significativas favorables a la génesis y activación de procesos erosivos y de transporte de materiales. Estos fuertes contrastes altimétricos son elocuentes de igual manera en los desniveles de los recorridos de las quebradas y ríos principales; de esta manera, las altitudes de las nacientes 
se ubican entre $1.200 \mathrm{msnm}$ y $2.550 \mathrm{msnm}$ y las de los desagües entre $25 \mathrm{msnm}$ y $125 \mathrm{msnm}$ en sus salidas en el frente montañoso, con promedios de 2.040,38 msnm y 48,85 msnm respectivamente. Los radios de relieve son indicadores indirectos del incremento de las pendientes de las vertientes en las cuencas y del gradiente hidráulico de los cursos de agua a medida que ascendemos en altura, y por ende del potencial erosivo en éstas. Por su parte, los valores de pendientes medias del relieve sugieren un alto potencial hidráulico para la activación de procesos de remoción en masa, principalmente aludes torrenciales $\mathrm{y}$ crecientes.

Con relación a los valores de concavidad de los perfiles longitudinales de los ríos y quebradas principales, indican para algunos cursos de agua un avanzado estadio de incisión o erosión vertical de sus flujos, condicionados principalmente por la poca resistencia de algunas unidades litológicas aflorantes, a los procesos erosivos. Para otros cursos de agua principales sus perfiles tienden a ser más bien convexos, lo cual se atribuye a un mayor control estructural o al afloramiento de litologías de mayor resistencia relativa a los procesos erosivos. Las pendientes medias de estos perfiles longitudinales y el fuerte contraste de gradientes medios entre los segmentos en los que éstos se dividieron, son indicadores de la alta probabilidad de estas quebradas y ríos a experimentar crecidas con hidrogramas de caudales picos elevados y de corta duración, altas velocidades medias del flujo, mayor capacidad de transporte de materiales y menores tiempos de concentración. Los valores obtenidos para el relieve máximo de las corrientes principales también expresan fuertes desniveles topográficos entre sus nacientes y sus desagües, condición que define pronunciados y variables gradientes topográficos a lo largo de sus recorridos en el sector montañoso de las cuencas. Las pendientes medias de los totales de corrientes de las redes de drenaje, denotan importantes gradientes hidráulicos que favorecen la rápida evacuación de las aguas de escorrentía concentradas.

Los valores de las integrales hipsométricas acusan un predominio de los procesos erosivos a lo largo del tiempo sobre las tasas de levantamiento tectónico en la región. Los coeficientes de masividad y orográficos presentan sus valores más elevados en las cuencas de menores superficies, como es el caso de las quebradas Osorio, Cariaco, El Cojo, Camurí Chiquito y Seca $(106,88 \mathrm{msnm} /$ $\mathrm{km}^{2}-195,57 \mathrm{msnm} / \mathrm{km}^{2}$ ), lo cual es debido a las elevadas altitudes medias en estas pequeñas cuencas, así como a los desniveles altimétricos máximos observados en las mismas. El relieve relativo como un resultado de dividir los valores de relieve máximo entre los perímetros de las cuencas, nos dice acerca de lo accidentado del relieve en estos sistemas, lo cual es interpretado de igual manera con los valores del número de rugosidad de Melton. Como se puede apreciar en los valores de los parámetros morfométricos relativos a la variable gradiente y forma del relieve de la cuenca, los mismos representan factores o elementos condicionantes del comportamiento torrencial de las cuencas estudiadas, así como de la generación de crecidas con caudales picos de magnitudes importantes y cortas duraciones, reducidos tiempos de concentración, y un alto potencial morfogenético expresado en la ocurrencia de episodios de procesos de remoción en masa, y en particular de aludes torrenciales.

Los valores de elongación son representativos de cuencas emplazadas en relieves montañosos con vertientes acusadas, predominio de la erosión regresiva en el mismo sentido del alargamiento de las cuencas, y control estructural. Los coeficientes de compacidad señalan que las formas de las cuencas distan en gran medida de la circularidad a excepción de las de las quebradas San Julián y Seca, por lo que sus tiempos de concentración son mayores en comparación con otras cuencas de iguales áreas pero de formas más circulares. Sin embargo, como ya se discutió, las crecidas en estas cuencas dependen de las características y dimensiones de las tormentas, así como de las superficies de las mismas. Las cuencas con mayores índices de alargamiento presentan tendencias a generar hidrogramas de crecidas con picos menos pronunciados y de mayor duración, efecto contrario en las cuencas que tienden más bien hacia la circularidad y tienen redes de drenaje más abiertas.

Los valores del factor forma para algunas cuencas de drenaje es bastante bajo, lo que implica de igual manera una fuerte tendencia al alargamiento, y bajas probabilidades de experimentar frecuentes crecidas, debido a que su forma no permite exponer toda su superficie al radio de acción de una determinada tormenta. Sin embargo, estas afirmaciones son relativas, ya que depende del tamaño o extensión de la tormenta, de la duración e intensidad de la misma, y de las magnitudes extremas del fenómeno. Las cuencas más homogéneas tienden también a tener respuestas hidrológicas controladas por una figura geométrica rectangular, con lo cual sus tiempos de concentración tenderán a ser mayores, es decir, habrá un mayor retardo en la acumulación de las aguas al paso 
de la corriente por su punto de desagüe. De cualquier modo la probabilidad de que se presenten crecidas con hidrogramas de picos pronunciados y de corta duración es alta, aunado a las características del relieve ya discutidas, que contribuyen en gran medida a este comportamiento hidrológico e hidráulico. Por otro lado, las formas de las cuencas de este estudio tienden a producir hidrogramas de crecidas asimétricos, es decir, con tiempo desde el inicio de la crecida al pico de la misma, mayor que el tiempo del pico a la recesión del hidrograma.

En conjunto, los parámetros de la variable extensión de la red de drenaje representan a un grupo de atributos geométricos que explican el espaciamiento y longitud de un sistema de drenaje, los cuales son de gran influencia en el control de las respuestas hidrológicas (magnitudes y características) de las cuencas. Las longitudes de los cursos de agua principales representan una condición que favorecen el rápido arribo de las crecientes a las salidas de las quebradas y ríos principales en el frente de montaña y en el ápice de sus abanicos. Las longitudes totales de las corrientes de las redes de drenaje son de magnitudes importantes, lo cual determina las súbitas respuestas hidrológicas de estos sistemas frente a las aguas pluviales, evacuadas rápidamente por redes amplias y altamente ramificadas. Los cursos de agua principales son básicamente de trayectorias rectilíneas y/o de muy baja sinuosidad, carácter morfométrico que determina la efectividad de los ríos y quebradas del sector para el rápido desagüe de sus crecidas y cargas sólidas.

Entre los factores que controlan la densidad de drenaje en el área de estudio, el de mayor peso está representado por la alta susceptibilidad de algunas litologías a los procesos erosivos, y el fracturamiento (patrones de diaclasas) de los mismos. De esta forma, a pesar de las escasas precipitaciones que se registran en el sector, aunado a la existencia de formaciones vegetales boscosas en la parte alta de las cuencas que favorecen a los procesos de infiltración más que a la escorrentía superficial, la densidad de drenaje presenta valores nada despreciables, producto del control geológico. Este parámetro indica también que una parte muy importante de las superficies de las cuencas experimenta escorrentía concentrada, por lo que es de suponer altas tasas de erodabilidad en todas sus superficies e inestabilidad morfogenética, y por ende gastos sólidos significativos en presencia de tormentas de lluvias de alta intensidad y duración.

Solo eventos hidrometeorológicos similares en magnitud e intensidad al observado en Diciembre de
1999 en el estado Vargas, podrían producir la erosión y el transporte de elevados volúmenes de sedimentos y agua, ocasionado por la saturación hídrica del material de alteración de las vertientes y cauces en estos sistemas hidrogeomorfológicos. Desde el punto de vista de las respuestas hidrológicas de las cuencas, estos valores de densidad de drenaje indican que en general en esos sistemas se generan crecidas con hidrogramas de picos elevados y reducidos tiempos de concentración, condicionados además por las características del relieve (pendientes), el tamaño de las cuencas y las características (intensidad y duración de las lluvias) de las tormentas que las puedan generar.

Los valores obtenidos como órdenes de las cuencas son indicadores importantes de la extensión y ramificación de las redes de drenaje, considerando las pequeñas superficies de estos sistemas, así como de alta probabilidad a experimentar crecidas con hidrogramas de picos significativos. Vistas las redes de drenaje bajo la totalidad del número de cauces de todos los órdenes, advierten sobre la eficacia de éstas para desaguar caudales importantes y acarrear elevados montos de sedimentos, con lo cual sus probabilidades respecto a la activación de procesos de remoción en masa y en particular de aludes torrenciales, son altas. Las relaciones de bifurcación media y entre número de corrientes de órdenes sucesivos reafirman la alta probabilidad de las cuencas a experimentar crecidas con caudales pico importantes, así como cortos tiempos de concentración. Por otra parte, hay que destacar que en general, todos los cursos de agua que conforman a las redes de drenaje del sector de estudio son de cortos recorridos, lo cual condiciona respuestas hidrológicas de magnitudes importantes en tiempos muy cortos.

La distribución clinométrica entre los órdenes sucesivos de las corrientes de las redes de drenaje, tiene una repercusión muy importante en el comportamiento hidrológico e hidráulico de las cuencas estudiadas, ya que por el hecho de presentar las corrientes de orden 1 y 2 las mayores pendientes y estar más cercanas a los perímetros de los sistemas, implican altas velocidades de los flujos activados por las aguas pluviales, así como rápidas concentraciones de éstos en las corrientes de órdenes mayores, más cercanas a los desagües de las cuencas en el frente de montaña.

El número de corrientes de un determinado orden de una red de drenaje por unidad de área, nos da una idea de los sectores o espacios bien drenados dentro de una cuenca, por lo general estos se ubican hacia las partes más 
altas de los sistemas, bordeando a los perímetros de las mismas, consideración que puede ser apreciada cuando observamos los datos correspondientes a las frecuencias de las corrientes de órdenes sucesivos, lo cual aunado a la distribución de las pendientes medias de las corrientes según sus órdenes, definen condiciones propicias para la generación de crecidas con hidrogramas de picos máximos de magnitudes resaltantes. Así mismo, las frecuencias medias de las corrientes totales de las redes de drenaje y los coeficientes de torrencialidad, implican sistemas hidrogeomorfológicos con buen drenaje que determinan escenarios para la ocurrencia de crecientes y aludes torrenciales, y cortos tiempos de concentración.

Los coeficientes de almacenamiento se corresponden con los valores medios a altos de las densidades de drenaje y las altas pendientes en general en todas las cuencas, con lo cual los procesos de escorrentía se ven favorecidos frente a los de infiltración, determinando a su vez que grandes porcentajes de los eventos de precipitaciones (lluvia efectiva) se transformen en caudales. Finalmente, los anchos máximos de las secciones hidráulicas de interés guardan relación directa con las magnitudes de las crecidas, por lo que dichas amplitudes son variables y móviles dependiendo de las características de los eventos que los afectan.

\section{Conclusiones}

Los sistemas hidrogeomorfológicos considerados en este estudio a pesar de ser de pequeñas dimensiones, albergan redes de drenaje de extensiones importantes que exhiben patrones de arreglos y organizaciones espaciales de tipo subdendríticos a subparalelos. El patrón subdendrítico acusa el control litológico en el desarrollo de ese tipo de arreglo, resultante de la susceptibilidad de la mayoría de las unidades litológicas aflorantes en las cuencas en combinación con las altas pendientes topográficas, determinando redes muy ramificadas que condicionan respuestas hidrológicas rápidas y agresivas, así como menores tiempos de concentración.

Las quebradas y ríos del sector de estudio son cursos de agua de muy cortos recorridos desde sus nacientes hasta sus salidas en el frente de montaña, e incluso considerándolas hasta sus desembocaduras en el mar, a lo largo de los cuales exhiben fuertes cambios de pendientes y por ende de sus gradientes hidráulicos con valores altos, típicos de sistemas torrenciales de ambientes montañosos con características del relieve muy marcadas, determinantes con gran peso en la generación de respuestas hidrológicas súbitas que muestran hidrogramas de crecidas de pronunciados picos máximos instantáneos, y muy cortos tiempos de concentración.

En atención a los parámetros morfométricos de las cuencas y sus redes de drenaje, y en específico a los referidos a la variable escala de la cuenca, estos sistemas hidrogeomorfológicos califican en la categoría de microcuencas debido a sus pequeñas dimensiones; con relación a los parámetros de la variable gradiente y forma del relieve, las definen como espacios topográficamente muy accidentados de fuertes pendientes y grandes desniveles altitudinales; los parámetros de la variable forma de la cuenca señalan que se trata de sistemas de morfologías planimétricas semi-circulares a semi-alargadas; en el caso de los parámetros de la variable extensión de la red de drenaje, indican sistemas de desagüe de ramificaciones y densidades considerables con cortas longitudes y canales de escasa sinuosidad (rectilíneos); y para el caso de la variable orden y magnitud de la cuenca de drenaje, sus parámetros indican redes de altas magnitudes y órdenes, así como elevados niveles de torrencialidad.

Los parámetros morfométricos relacionados con la geometría de los sistemas (grupo de parámetros morfométricos correpondientes a la variable escala de la cuenca: Área, perímetro, longitud, ancho y diámetro), son los que determinan en mayor proporción condiciones particulares que favorecen la ocurrencia de crecidas con hidrogramas de picos pronunciados y corta duración, así como menores tiempos de concentración en presencia de tormentas significativas en intensidad, duración y dimensiones, debido a que ellos son los que determinan las superficies de captación de las aguas pluviales. Además de los parámetros morfométricos que se agrupan en la variable escala de la cuenca, otros correspondientes a variables que definen atributos distintos de estos sistemas hidrogeomorfológicos, contribuyen de igual manera con pesos significativos en el control de las magnitudes y características de las respuestas hidrológicas y morfodinámicas de las cuencas.

Estos parámetros morfométricos están representados en específico por las pendientes de los perfiles longitudinales de las quebradas y ríos principales, lo pronunciado del relieve montañoso (coeficiente de masividad, coeficiente orográfico y número de rugosidad de Melton), las cortas longitudes de los recorridos de los cursos de agua principales, los altos órdenes de las cuencas considerando que se trata de sistemas pequeños, 
el número total de corrientes de las redes de drenaje y las magnitudes de las mismas. En breves palabras, las respuestas morfodinámicas e hidrológicas de las cuencas estudiadas son condicionadas y controladas por sus parámetros morfométricos y los de sus redes de drenaje.

\section{Referencias Bibliográficas}

AMEND, S. Parque Nacional El Ávila. Caracas: Stephan y Thora Amend, 1991. 176 p. (Parques Nacionales y Conservación Ambiental $\mathrm{N}^{\mathrm{o}}$ 2).

ANDRESSEN, R.; PULWARTY, R. Análisis de las lluvias excepcionales causantes de la tragedia del estado Vargas, Venezuela, en Diciembre de 1999. En: SIMPOSIO INTERNACIONALDE DESARROLLO SUSTENTABLE, 4., 2001, Mérida. p. 148-167.

AYALA, R.; PÁEZ, G.; ARAQUE, F. Análisis geomorfológico de la microcuenca El Guayabal, a propósito de la ocurrencia de las lluvias excepcionales de febrero de 2005, cuenca del río Mocotíes, estado Mérida - Venezuela. Revista Geográfica Venezolana, Mérida, v. 48, n. 1, p. 59-82. 2007.

CAMPO, A.; ALDALUR, N.; FERNÁNDEZ, S. Morfometría fluvial aplicada a una cuenca urbana en Ingeniero White, República Argentina. Investigaciones Geográficas, Ciudad de México, n. 77, p. 7-17. 2012.

CENTRO DE PROCESAMIENTO DIGITAL DE IMÁGENES.

Landsat 7 ETM: resolución espacial 30 metros, multiespectral combinación bandas 543 [Imagen de satélite]. Baruta: Centro de Procesamiento Digital de Imágenes. 2002.

DIRECCIÓN DE CARTOGRAFÍA NACIONAL. Hojas II-8, III-8, IV-8, I-9, II-9, III-9, IV-9, I-10, II-10, III-10, IV-10, I-11, II-11, III-11, IV-11, I-12, II-12, III-12, IV-12, I-13, II-13, III-13 y IV-13, escala 1:5.000 [Planos topográficos]. Caracas: Dirección de Cartografía Nacional. 1958.

DIRECCIÓN DE CARTOGRAFÍA NACIONAL. Hojas 6847-IVSO 23 de Enero, 6847-I-SO Curupao, 6847-IV-NE El Caribe, 6847-IV-SE Los Chorros, 6847-IV-NO Maiquetía y 6847-INO Naiguatá, escala 1:25.000 [Cartas topográficas]. Caracas: Dirección de Cartografía Nacional. 1979.

ELIZALDE, G.; VILORIA, J.; ROSALES, A. Geografía de suelos de Venezuela. En: GeoVenezuela 2: medio físico y recursos ambientales. Caracas: Fundación Empresas Polar, 2007. p. 402537.

ESPER, M. Morphometric analysis of Colangüil river basin and flash flood hazard, San Juan, Argentina. Environmental Geology, New York, n. 55, p. 107-111. 2008.
FARFÁN, F.; URBINA, L.; FERREIRA, S.; BRANDAN, M. Caracterización y red de drenaje de la subcuenca del río Tin-Tin, PN Los Cardones, Salta. Revista Científica de Educación, Catamarca, v. 5, n. 16, p. 7-21. 2010.

FOGHIN, S. Algunas consideraciones meteorológicas acerca de la catástrofe del Estado Vargas en Diciembre de 1999. Aula y Ambiente, Caracas, año 1, n. 1, p. 93-98. 2001.

FOGHIN, S. Tiempo y clima en Venezuela: aproximación a una geografía climática del territorio venezolano. Caracas: Universidad Pedagógica Experimental Libertador, Instituto Pedagógico de Miranda José Manuel Siso Martínez, Subdirección de Investigación y Postgrado, Caracas, Venezuela, 2002. 159 p. (Colección Clase Magistral).

GENCHI, S.; CARBONE, M.; PICCOLO, M.; PERILlO, G. Hydrologic response of the drainage basins that intersect Las Grutas town, Argentina. Investigaciones Geográficas, Ciudad de México, n. 75, p. 23-36. 2011.

GOBERNACIÓN DEL DISTRITO FEDERAL. Hojas B-42, C-42, D-42, E-42, B-43, C-43, D-43, E-43, B-44, C-44, D-44, B-45, B-46, B-47, B-48 y B-49, escala 1:5.000 [Planos topográficos]. Caracas: Gobernación del Distrito Federal. 1984.

GOUVEIA, C. DE. Susceptibilidade morfométrica de bacias de drenagem ao desenvolvimento de inundações em áreas costeiras. Revista Brasileira de Geomorfologia, São Paulo, n. 1, p. 45-61. 2005.

GUEVARA, E.; CARTAYA, H. Hidrología ambiental. Valencia: Facultad de Ingeniería de la Universidad de Carabobo, 2004. 497 p.

GUEVARA, J. Geografía de las regiones Central y Capital. Caracas: Seix Barral, 1983. 344 p.

HIDALGO, L. La gran lluvia venezolana de diciembre 1999. En: LÓPEZ, J.; GARCÍA, R. (Coord.). Los aludes torrenciales de diciembre 1999 en Venezuela. Caracas: Universidad Central de Venezuela, Facultad de Ingeniería, Instituto de Mecánica de Fluidos, 2006. p. 68-73.

INSTITUTO GEOGRÁFICO DE VENEZUELA SIMÓN BOLÍVAR. Fotografías N No 1040 a 1043, 1164 a 1166, 1168 a 1173, 1175 a 1177,1179 a 1183,1186 a $1188,1190-1191,1195$ a 1197, 2367 a 2369, 2396 a 2398 y 2406-2407, escala 1:5.000, misión aerofotográfica 030602 [Fotografías aéreas]. Caracas: Instituto Geográfico de Venezuela. 1999-2000.

INSTITUTO GEOGRÁFICO DE VENEZUELA SIMÓN BOLÍVAR. Caracas y alrededores, escala 1:100.000 [Mapa]. Caracas: Instituto Geográfico de Venezuela. 2003.

MÉNDEZ, W.; CÓRDOVA, J.; CARTAYA, S.; PACHECO, 
H. Geomorfología y respuesta hidrológica de la microcuenca de drenaje de la quebrada Curucutí, estado Vargas, Venezuela. Revista de la Facultad de Ingeniería, Caracas, v. 22, n. 1, p. 5-20. 2007.

MÉNDEZ, W.; FERNÁNDEZ, E.; DÍAZ, Y.; ARÉVALO, M.; CORREA, N. Amenaza por crecidas torrenciales en el extremo occidental de la vertiente sur del macizo "El Ávila", Distrito Capital, Venezuela. En: CONGRESO VENEZOLANO DE GEOCIENCIAS, 1., 2011, Caracas.

MÉNDEZ, W.; MARCUCCI, E. Análisis morfométrico de la microcuenca de la quebrada Curucutí, estado Vargas, Venezuela. Revista Geográfica Venezolana, Mérida, v. 47, n. 1, p. 29-55. 2006.

MINISTERIO DEL PODER POPULAR PARAELAMBIENTE, DIRECCIÓN GENERAL DE CUENCAS, DIRECCIÓN DE HIDROLOGÍA Y METEOROLOGÍA. Estaciones Maiquetía, Maiquetía-Aeropuerto, La Guaira-Estación GFG, Macuto, Trincheras, Los Castillitos, Hotel Humboldt, Fila Maestra, Caraballeda, La Guaira-Electricidad, Uria, Naiguatá, Río Grande, María Isabel, Naiguatá-Estanque, Piedra Azul I, Piedra Azul II, Piedra Azul III, Caracas-El Ávila, Los Corales y Ojo de Agua [Datos climatológicos]. Caracas: Dirección de Hidrología y Meteorología. 2011.

POTENCIANO, A.; GARZÓN, G. Parámetros geomorfológicos y regresión múltiple en el comportamiento hidrológico de caudales en las cuencas altas de los ríos Tajo y Guadiana. Geogaceta, Salamanca, n. 38, p. 259-262. 2005.

ROMSHOO, S.; BHAT, S.; RASHID, I. Geoinformatics for assessing the morphometric control on hydrological response a watershed scale in the Upper Indus Basin. Journal of Earth System Sciences, Bangalore, v. 121, n. 3, p. 659-686. 2012.

SERVICIO AUTÓNOMO DE GEOGRAFÍA Y CARTOGRAFÍA NACIONAL. Hojas 6847-IV-NE Caraballeda, 6847-IV-SO Caracas, 6847-I-SO Curupao, 6847-IV-NO La Guaira, 6847-IVSE Los Chorros y 6847-I-NO Naiguatá, escala 1:25.000 [Ortofotomapas]. Caracas: Servicio Autónomo de Geografía y Cartografía Nacional. 1995.

SILVA, A. DA; HERPIN, U.; MARTINELLI, L. Morphometric characteristics of seven meso-scale river basins in state of São Paulo (Southeastern Brazil). Caminhos de Geografia, Uberlândia, v. 3 , n. 17 , p. $20-30,2006$.
STEYERMARK, J.; HUBER, O. Flora del Ávila: flora y vegetación de las montañas del Ávila, de la Silla y del Naiguatá. Caracas: Sociedad Venezolana de Ciencias Naturales, Völlmer Foundation, Ministerio del Ambiente y de los Recursos Naturales Renovables, 1978. 655 p.

STRAHLER, A. Geografía física. 7 ed. Barcelona: Omega S. A., 1985.767 p.

URBANI, F. Consideraciones geológicas de la catástrofe del estado Vargas de diciembre de 1999. En: SEMINARIO VENEZOLANO DE GEOTECNIA: CALAMIDADES GEOTÉCNICAS URBANAS CON VISIÓN AL SIGLO XXI, LA EXPERIENCIA PARA PROYECTOS DEL FUTURO, 16., 2000, Caracas. Memorias del XVI Seminario Venezolano de Geotecnia. Caracas: Sociedad Venezolana de Geotecnia, 2000. p. 179-193.

URBANI, F. Geología del estado Vargas y las unidades ígneometamórficas de la Cordillera de la Costa. En: COLOQUIO SOBRE MICROZONIFICACIÓN SÍSMICAY JORNADAS DE SISMOLOGÍA HISTÓRICA, 3., 2002, Caracas. Memorias del III Coloquio sobre Microzonificación Sísmica y III Jornadas de Sismología Histórica. Caracas: Fundación Venezolana de Investigaciones Sismológicas, 2002. p. 236-240.

URBANI, F.; RODRÍGUEZ, J.; BARBOZA, L.; RODRÍGUEZ, S.; CANO, V.; MELO, L.; CASTILLO, A.; SUÁREZ, J.; VIVAS, V.; FOURNIER, H. Geología del estado Vargas, Venezuela. En: LÓPEZ, J.; GARCÍA, R. (Coord.). Los aludes torrenciales de diciembre 1999 en Venezuela. Caracas: Universidad Central de Venezuela, Facultad de Ingeniería, Instituto de Mecánica de Fluidos, 2006. p. 133-156.

VÉLEZ, M.; VÉLEZ, J. Geomorfología de cuencas. En VÉLEZ, M.; VÉLEZ, J. (Comp.). Hidrología (I-1060): notas del curso de Hidrología de la profesora María Victoria Vélez O. Medellín: Universidad Nacional de Colombia, Facultad de Minas, Unidad de Hidráulica. s. f. Disponible en: $<$ http://poseidon.unalmed. edu.co/Materias/hidrología/4_Geomorfologia.pdf $>$. Acceso en: 30 ene. 2015.

YUNUS, A.; OGUCHI, T.; HAYAKAWA, Y. Morphometric analysis of drainage basins in the Western Arabian Peninsula using multivariate statistics. International Journal of Geosciences, Wuhan, n. 5, p. 527-539. 2014. 